\title{
Retrospective dosimetry of Iodine-131 exposures using Iodine-129 and Caesium-137 inventories in soils - A critical evaluation of the consequences of the Chernobyl accident in parts of Northern Ukraine
}

\author{
R. Michel ${ }^{\text {a, }}{ }^{*}$, A. Daraoui ${ }^{\text {a }}$, M. Gorny ${ }^{\text {a }}$, D. Jakob ${ }^{\text {a }}$, R. Sachse ${ }^{\text {a }}$, L.D. Romantschuk ${ }^{\text {b }}$, \\ V. Alfimov ${ }^{\text {C }}$, H.-A. Synal ${ }^{\text {c }}$ \\ ${ }^{a}$ Institut für Radiooekologie und Strahlenschutz (IRS), Leibniz Universität Hannover, Herrenhaeuser Str. 2, D-30419 Hannover, Germany \\ b State University of Agriculture and Ecology, Stari Bulvar 7, Zhitomir 262 001, Ukraine \\ ${ }^{\mathrm{c}}$ Laboratory of Ion Beam Physics, ETH-Zurich, Otto-Stern-Weg 5, CH-8093 Zurich, Switzerland
}

\section{A R T I C L E I N F O}

\section{Article history:}

Received 26 April 2015

Received in revised form

20 July 2015

Accepted 22 July 2015

Available online 7 August 2015

\section{Keywords:}

Iodine-129

Iodine-131

Caesium-137

Accelerator mass spectrometry

ICP-MS

Retrospective dosimetry

Radionuclide migration

\begin{abstract}
A B S T R A C T
The radiation exposure of thyroid glands due to ${ }^{131}$ I as a consequence of the Chernobyl accident was investigated retrospectively based on ${ }^{129} \mathrm{I}$ and ${ }^{137} \mathrm{Cs}$ inventories in soils in Northern Ukraine. To this end, soil samples from 60 settlements were investigated for ${ }^{129} \mathrm{I},{ }^{127} \mathrm{I}$, and ${ }^{137} \mathrm{Cs}$ by AMS, ICP-MS and gammaspectrometry, respectively. Sampling was performed between 2004 und 2007.

In those parts of Northern Ukraine investigated here the ${ }^{129} \mathrm{I}$ and ${ }^{137} \mathrm{Cs}$ inventories are well correlated, the variability of the individual ${ }^{129} \mathrm{I} /{ }^{137} \mathrm{Cs}$ ratios being, however, high. Both the ${ }^{129} \mathrm{I}$ and ${ }^{137} \mathrm{Cs}$ inventories in the individual 5 samples for each settlement allowed estimating the uncertainties of the inventories due to the variability of the radionuclide deposition and consequently of the retrospective dosimetry.

Thyroid equivalent doses were calculated from the ${ }^{129} \mathrm{I}$ and the ${ }^{137} \mathrm{Cs}$ inventories using aggregated dose coefficients for 5-year old and 10-year-old children as well as for adults. The highest thyroid equivalent doses (calculated from ${ }^{129}$ I inventories) were calculated for Wladimirowka with 30 Gy for 5-years-old children and 7 Gy for adults. In 35 settlements of contamination zone II the geometric mean of the thyroid equivalent doses was 2.0 Gy for 5 -years-old children with a geometric standard deviation (GSD) of 3.0. For adults the geometric mean was $0.47 \mathrm{~Gy}$ also with a GSD of 3.0. In more than 25 settlements of contamination zone III the geometric means were 0.82 Gy for 5 -years old children with a GSD of 1.8 and 0.21 Gy for adults (GSD 1.8).

For 45 settlements, the results of the retrospective dosimetry could be compared with thyroid equivalent doses calculated using time-integrated ${ }^{131}$ I activities of thyroids which were measured in 1986. Thus, a critical evaluation of the results was possible which demonstrated the general feasibility of the method, but also the associated uncertainties and limitations.
\end{abstract}

(C) 2015 Elsevier Ltd. All rights reserved.

\section{Introduction}

This work is part of a radioecological project by which the environmental behaviour of various radionuclides released by the Chernobyl accident and the resulting radiation exposure of the inhabitants in the highly contaminated areas in Northern Ukraine were studied; e.g. Schmidt et al. (1998), Filss et al. (1998), Slavov et al. (1999), Botsch et al. (2000), Handl et al. (2003), Mewis

\footnotetext{
* Corresponding author. Wilh.-Henze-Weg 14, D-31303 Burgdorf, Germany. E-mail address: michel@irs.uni-hannover.de (R. Michel).
}

(2004), and Hippler (2006). These investigations were aimed on the evaluation of the exposures of inhabitants of contamination zones II and III in Northern Ukraine due to ${ }^{137} \mathrm{Cs},{ }^{90} \mathrm{Sr}$, and actinide isotopes more than a decade after the accident. With the goal of retrospective dosimetry of ${ }^{131}$ I exposures shortly after the accident we analysed ${ }^{127}$ I and ${ }^{129}$ I in soils from Russia and Northern Ukraine (Michel et al., 2005). Results were obtained for exposure to ${ }^{131}$ I of people living in the Korosten and Narodici districts (Zhitomir region) of Northern Ukraine.

After a reactor accident with massive releases of radionuclides to the environment, reliable estimates of the thyroid exposures due to inhalation and ingestion of ${ }^{131} \mathrm{I}$ are essential to assess the risk of 
thyroid cancer. Repeated direct measurements of the ${ }^{131}$ I activity in the thyroids of the affected population provide the best means for reliable estimates of the thyroid exposure. However, comprehensive measurements of the thyroid activities in an entire population are difficult to organize in the immediate aftermath of such an emergency. Moreover, the short half-life of ${ }^{131} \mathrm{I}$ (8.02 days) does not allow extending such measurements over larger time spans.

Consequently, one has to rely to a large degree on retrospective dosimetry on the basis of the environmental abundances of longlived radionuclides released in the accident. After the Chernobyl accident, ${ }^{129} \mathrm{I}\left(T_{1 / 2}=15.7 \mathrm{Ma}\right)$ and ${ }^{137} \mathrm{Cs}\left(T_{1 / 2}=30.17 \mathrm{a}\right)$ were suitable radionuclides for this purpose. As volatile elements they were released in large amounts together with ${ }^{131}$ I during the initial explosion, the subsequent graphite burning and melt-down of the residual core, and they were transported over large distances. By fall-out and wash-out large parts of the northern hemisphere and in particular of Europe were contaminated. Actinide elements and ${ }^{90} \mathrm{Sr}$ were not suited for this purpose since they were strongly fractionated relative to iodine in the release process due to their lower volatility. Also the transport, fall-out and wash-out processes of ${ }^{90} \mathrm{Sr}$ and actinide elements differ strongly from those of iodine and caesium. See UNSCEAR (2000) for a detailed assessment of the accident.

Undisturbed soils can be used as archives for the fall-out of longlived radionuclides for the purpose of retrospective dosimetry. In order to retrospectively estimate radiation exposures using longlived radionuclides in the soil archives, radioecological modelling is needed to describe the pathways of the radionuclides through the environment to humans. This appears reasonably feasible if the exposure is dominated by external irradiation or by the ingestion pathway since data on the actual behaviour (occupancy and shielding factors), consumption habits (e.g. milk and green vegetables) as well as land and animal use can be retrospectively surveyed. The contribution to the exposure via the inhalation pathway is more difficult to estimate since it requires information about the transition of the radioactive plumes and the actual weather conditions, which involves meteorological observations or modelling.

The analysis of the long-lived radionuclide ${ }^{129}$ I in soils is - in principle - the best method for the retrospective dosimetry of the radiation exposure caused by ${ }^{131}$ I long after the release in accidents or incidents because the physico-chemical properties of both nuclides are practically identical. However, there are several requirements for this retrospective dosimetry to be feasible. The ${ }^{129} \mathrm{I}$ from the accident must not have disappeared from the analysed soil horizons by migration into deeper soil layers and it must be distinguishable from potentially existing fall-out prior to accident. Finally, the radioecological modelling connecting the inventory of ${ }^{131}$ I derived from the observed ${ }^{129}$ I deposition densities with the thyroid dose must be as realistic as possible on the basis of the available information.

The environmental abundances of ${ }^{129}$ I and its pathways through the different environmental compartments represent a scientifically quite complicated case because of its various natural and manmade sources and its poorly understood environmental chemistry. It is produced in nature by cosmic-ray induced spallation of xenon in the atmosphere and by spontaneous fission in the geosphere. The natural abundances of ${ }^{129} \mathrm{I}$ have been globally enhanced by ${ }^{129} \mathrm{I}$ released by man into the environment. Man-made ${ }^{129}$ I originates primarily from induced fission of ${ }^{235} \mathrm{U}$ and ${ }^{239} \mathrm{Pu}$. Explosions of nuclear weapons, the Chernobyl accident and, most importantly, releases from reprocessing plants have raised the environmental abundances locally and globally by orders of magnitude, although this radionuclide is not yet of radiological relevance except for the closest proximity to reprocessing plants. Man-made ${ }^{129}$ I enters the environmental iodine cycles and changes the environmental iodine isotopic abundances. See Schmidt et al. (1998), Michel et al. (2005, 2012) for details and references.

There are several other publications dealing with the retrospective dosimetry of ${ }^{131}$ I exposures using ${ }^{129}$ I data. Straume et al. (1996, 2006), Robl et al. (1997), and Mironov et al. (1999, 2002) investigated the situation in Belarus, Pietrzak-Flis et al. (2003) in Poland. Endo et al. (2008) used ${ }^{129}$ I for the retrospective dosimetry of the inhabitants of Dolon near Semipalatinsk in Kazakhstan. Dolon is close to the nuclear test site where 450 tests of nuclear weapons were performed between 1949 and 1989. Reithmeier et al. (2002) dealt with the general methodology of ${ }^{131}$ I dose reconstruction in the former Soviet-Union by measurement of ${ }^{129}$ I. Most of the earlier work aimed at evaluating the feasibility of ${ }^{129} \mathrm{I}$ retrospective dosimetry and on determining some of the input quantities needed. Only Robl et al. (1997) and Pietrzak-Flis et al. (2003) did complete evaluations ending up with thyroid dose estimates.

During recent years the retrospective dosimetry of ${ }^{131}$ I exposures via ${ }^{129}$ I has again become of high interest because the thyroid exposures after the Fukushima Dai-Ichi accident were insufficiently measured and have to be evaluated by retrospective dosimetry. Investigations with the goal of retrospective dosimetry are under way (Miyake et al., 2012).

More often than ${ }^{129} \mathrm{I},{ }^{137} \mathrm{Cs}$ deposition has been used to estimate thyroid exposures to ${ }^{131}$ I after the Chernobyl accident because ${ }^{137} \mathrm{Cs}$ is much simpler to analyse. Kruk et al. (2004) summarized the respective earlier work and performed new model calculations for Belarus. They considered the actual weather and ecological conditions at the time of the accident and - as far as available - information about the fall-out ratio of ${ }^{131} \mathrm{I}$ and ${ }^{137} \mathrm{Cs}$. The latter ratio is the crucial quantity if ${ }^{137} \mathrm{Cs}$ is used for the retrospective dosimetry of ${ }^{131}$ I exposures. The radionuclides showed considerable variability due to time-dependent elemental fractionation during emission and atmospheric transport. UNSCEAR (2000) reported values between 10 and 30 for the ${ }^{131} \mathrm{I} /{ }^{137} \mathrm{Cs}$ ratio and Talerko (2005) calculated ratios of ${ }^{131} \mathrm{I}$ and ${ }^{137} \mathrm{Cs}$ inventories between 5 and 28 for Ukraine taking into account the detailed emission history and the actual weather conditions.

In this work, we continue our earlier investigations (Michel et al., 2005) by a systematic study of a large number of settlements in the contamination zones II and III of Northern Ukraine. The first goal was to obtain thyroid dose estimates for an area where excessive ${ }^{131}$ I exposures occurred in 1986 combined with estimates of the uncertainties of the exposures due to the variability of the environmental radioactivity. The concerned population was neither warned after the accident nor were there any recommendation for protective measures.

A second goal was to investigate whether the alternative approach to retrospective dosimetry of ${ }^{131}$ I exposure would work, namely to use ${ }^{137} \mathrm{Cs}$ in soils as a basis to estimate the doses.

Thirdly, we intended to perform a critical comparison of the accuracy of retrospective dosimetry using ${ }^{129} \mathrm{I}$ (or ${ }^{137} \mathrm{Cs}$ ). This was possible by comparing our results with thyroid dose estimates based on settlement-averaged results of direct measurements of ${ }^{131}$ I in human thyroids performed in 1986 (Likhtarov et al., 1994) and evaluated later by Jacob et al. (2006).

Direct measurements of thyroid activities after the Chernobyl accident revealed a high variability of individual exposures compared to the results of deterministic model calculations of the mean thyroid exposures; e.g. Likhtarov et al. (1994). This variability depends - among many behavioural factors - on the small-scale variability of the environmental radioactivity. Since the latter is quantified in this work this will be a first step to assess the uncertainties of thyroid exposure estimates.

The paper is structured in the following way. After describing 
the experimental procedures and presentation of the experimental results for the ${ }^{129}$ I and ${ }^{137} \mathrm{Cs}$ inventories, the critical question of the pre-Chernobyl fall-out of ${ }^{129} \mathrm{I}$ and ${ }^{137} \mathrm{Cs}$ is discussed and the ${ }^{131} \mathrm{I}$ inventories inferred. Then, the modelling of thyroid exposures is described and the resulting thyroid doses are presented. Finally, a comparison of the thyroid doses derived from direct measurements of the thyroid ${ }^{131}$ I activities with the results of the retrospective dosimetry on the basis of ${ }^{129} \mathrm{I}$ and ${ }^{137} \mathrm{Cs}$ is made. In conclusion, the pros and cons of the retrospective dosimetry of thyroid exposures are discussed.

\section{Experimental}

Between 2004 and 2007 soil samples were taken in 60 settlements in Northern Ukraine located in the contamination zones II, with ${ }^{137} \mathrm{Cs}$ deposition densities between $555 \mathrm{kBq} \mathrm{m}^{-2}$ and $1480 \mathrm{kBq} \mathrm{m}{ }^{-2}\left(15-40 \mathrm{Ci} \mathrm{km}^{-2}\right)$, and III, with ${ }^{137} \mathrm{Cs}$ deposition densities between $185 \mathrm{kBq} \mathrm{m}^{-2}$ and $555 \mathrm{kBq} \mathrm{m}^{-2}\left(5-15 \mathrm{Ci} \mathrm{km}^{-2}\right.$ ); categorization according to a Law of Ukraine (1991). Fig. 1 shows the locations of the settlements investigated, Table 1 gives the geographical coordinates. The settlements are located in an area of $50 \mathrm{~km} \times 50 \mathrm{~km}$ with distances between $50 \mathrm{~km}$ and $110 \mathrm{~km}$ from the Chernobyl NPP. A rough impression of the zones II and III may be found in Fig. 1 of Michel et al. (2005), detailed maps are given by the Ministry of Ukraine (2008). Since the zoning is very irregular in the area investigated in this work we omitted an indication of the zones in the figures. It can, however, easily be checked from Fig. 3 (upper panel) where the criterion for zone II of $>555 \mathrm{kBq} \mathrm{m}^{-2}$ is exceeded.

The inhabitants of contamination zone II were evacuated; those of contamination zone III got the right of voluntary relocation. The evacuation measures took place between 1986 and 2004. Between May 10 and May 28, 1986 some of the highly contaminated settlements of contamination zone II were evacuated. Among them were the following settlements investigated in this work: Schurba, Derkatschi, Wolodmiriwka, Nowe Scharno, Stare Scharno, Dowgij Lis, Omelniki, Motili and, partially, Polis'ke. The remaining settlements of contamination zone II were relocated only between 1989 and 2004. Also in contamination zone III, the inhabitants of Polis'ke and Rundnya Basars'ka were relocated during the years 1990 and 1991. It can therefore be assumed that the evacuation or relocation had no significant influence on the thyroid exposures from ${ }^{131} \mathrm{I}$.

All sampling sites were chosen at locations without bushes and trees with apparently constant land use and not affected by human activities during recent decades and which should represent undisturbed soils. In each settlement samples were taken at five locations to a depth of $40 \mathrm{~cm}$ under a base area of $20 \mathrm{~cm} \times 20 \mathrm{~cm}$. The five soil samples for each settlement were taken in a systematic way: one each at the entrance, the middle and the exit of the village and at the left and right side of it. In addition, three soil profiles were taken at Schurba, Dowgij-Lis and Hristiniwka in contamination zone II down to a depth of $2 \mathrm{~m}$. For the depth profiles, trenches were dug and mixed samples from different depth horizons were taken.

After removing any visible pieces of vegetation and determining the fresh weight, the material was dried at room temperature, milled, and thereafter sieved through a 2-mm mesh sieve. As it was not feasible to analyse all individual cores in detail for their depth dependence of ${ }^{127} \mathrm{I}$ and ${ }^{129} \mathrm{I}$, the ${ }^{137} \mathrm{Cs}$ activities, ${ }^{127}$ I concentrations and the ${ }^{129} \mathrm{I} /{ }^{127} \mathrm{I}$ isotopic ratios were measured for the 300 mixed core samples (60 settlements with 5 locations each).

The samples were analysed for ${ }^{129} \mathrm{I} /{ }^{127} \mathrm{I}$ isotopic ratios by accelerator mass spectrometry (AMS) using the TANDY AMS machine (Stocker et al., 2005), for ${ }^{127}$ I by inductively coupled plasma mass spectrometry (ICP-MS), and for ${ }^{137} \mathrm{Cs}$ by $\gamma$-spectrometry. For the ${ }^{137} \mathrm{Cs}$ analyses see Botsch et al. (2000) and Handl et al. (2003).
Reliable analytical protocols for ${ }^{129} \mathrm{I}$ and ${ }^{127} \mathrm{I}$ analyses in various environmental materials were established in our earlier work. Detailed descriptions of the sample preparations, the analytical techniques (AMS and ICP-MS), and quality control measures and on participation in round robin exercises (Roberts et al., 1997; Roberts and Caffee, 2000) are given elsewhere (Schmidt et al., 1998; Szidat et al., 2000a, 2000b, 2000c; Ernst et al., 2003).

Repeated analyses of reference materials were performed, using IAEA-Soil-375, and IAEA-Soil-385 which proved consistency of our analyses with our previous work and the data reported for these materials by Songsheng et al. (2005); for details see Daraoui (2010).

The ${ }^{129}$ I blank values of the total analyses were determined with Woodward iodine as trace catcher. Typical blank ${ }^{129} \mathrm{I} /{ }^{127} \mathrm{I}$ ratios of the total analyses performed in two different laboratories were in terms of geometric means and standard deviations ${ }^{1}$ $\left(2.6 \times 1.8^{ \pm 1}\right) \times 10^{-12}$ and $\left(2.5 \times 2.1^{ \pm 1}\right) \times 10^{-13}$. The mean ${ }^{129} \mathrm{I}$ contamination of a sample analysed as a consequence of the laboratory background as estimated from the blanks were $0.85 \mathrm{fg}$ and $4.35 \mathrm{fg}$, respectively. This is more than a factor of 1000 smaller than the amount of ${ }^{129}$ I found in the samples. For detailed data see Daraoui (2010).

Complete standard measurement uncertainties were derived according to the "ISO Guide to the expression of uncertainty in measurement" (ISO, 1995) taking into account all known sources of uncertainties. The average relative uncertainties were $4.1 \%$ in the case of ${ }^{127} \mathrm{I}, 4.3 \%$ in the case of ${ }^{129} \mathrm{I}$ and $3.3 \%$ for ${ }^{137} \mathrm{Cs}$. Characteristic limits such as decision thresholds, detection limits and limits of the coverage interval were calculated according to ISO 11929 (ISO, 2010). The decision thresholds and detection limits (assuming probabilities for wrong decisions of $\alpha=\beta=0.05$ ) were dominated by the uncertainties of the blank corrections. Typical detection limits of ${ }^{127} \mathrm{I},{ }^{129} \mathrm{I}$ and ${ }^{137} \mathrm{Cs}$ were $0.1 \mathrm{ng} \mathrm{g}{ }^{-1}, 40 \mathrm{nBq} \mathrm{kg}{ }^{-1}$ and $10 \mathrm{mBq} \mathrm{kg}{ }^{-1}$, respectively. For background information on the use of the characteristic limits see e.g. Michel (2000). Values of the characteristic limits obtained in the measurements of individual samples may be found elsewhere (Daraoui, 2010).

\section{Experimental results}

Details on the measured values of ${ }^{137} \mathrm{Cs}-,{ }^{40} \mathrm{~K}-,{ }^{127} \mathrm{I}-,{ }^{129} \mathrm{I}-\mathrm{con}-$ centrations, the ${ }^{129} \mathrm{I} /{ }^{127} \mathrm{I}$ ratios and measurement uncertainties can be found elsewhere (Daraoui, 2010). In summary, the ${ }^{137} \mathrm{Cs}$ activity concentrations were between $17 \mathrm{~Bq} \mathrm{~kg}{ }^{-1}$ and $32.3 \mathrm{kBq} \mathrm{kg}^{-1}$, those of ${ }^{4} \mathrm{~K}$ ranged from 19 to $826 \mathrm{~Bq} \mathrm{~kg}{ }^{-1}$ and those of ${ }^{129}$ I from 0.01 to $6.7 \mathrm{mBq} \mathrm{kg}{ }^{-1}$. The ${ }^{127} \mathrm{I}$ concentrations were between $0.02 \mathrm{mg} \mathrm{kg}^{-1}$ and $7.1 \mathrm{mg} \mathrm{kg}^{-1}$ and the ${ }^{129} \mathrm{I} /{ }^{127} \mathrm{I}$ isotopic ratios ranged from $1.2 \times 10^{-9}$ to $1.5 \times 10^{-6}$. Here, we deal first with the results of the three soil profiles investigated and then with the samples taken to determine inventories.

The results obtained for the three deep soil profile from DowgijLis, Hristiniwka and Schurba (numbers 3, 28, and 6, respectively, in Fig. 1) confirmed the observations made by our earlier work (Michel et al., 2005). More than $90 \%$ of the ${ }^{129}$ I and ${ }^{137} \mathrm{Cs}$ activities are still located in the topmost $40 \mathrm{~cm}$ of the soil profiles. The individual data ranged between $0.0021 \mathrm{mBq} \mathrm{kg}{ }^{-1}$ and $4.4 \mathrm{mBq} \mathrm{kg}^{-1}$ for ${ }^{129} \mathrm{I}$ and between $0.3 \mathrm{~Bq} \mathrm{~kg}^{-1}$ and $6.6 \mathrm{kBq} \mathrm{kg}^{-1}$ for ${ }^{137} \mathrm{Cs}$. Thus, activities measured in samples down to $40 \mathrm{~cm}$ depth can be used to

\footnotetext{
1 In this paper, we use the convenient notation of e.g. $2.6 \times 1.8^{ \pm 1}$ to present geometric means and geometric standard deviations in analogy to the frequently used notation of arithmetic means and standard deviations. For an assumed logarithmic normal distribution, one obtains an interval containing about $66 \%$ of the data by multiplying, respectively by dividing, the geometric mean by the geometric standard deviation.
} 


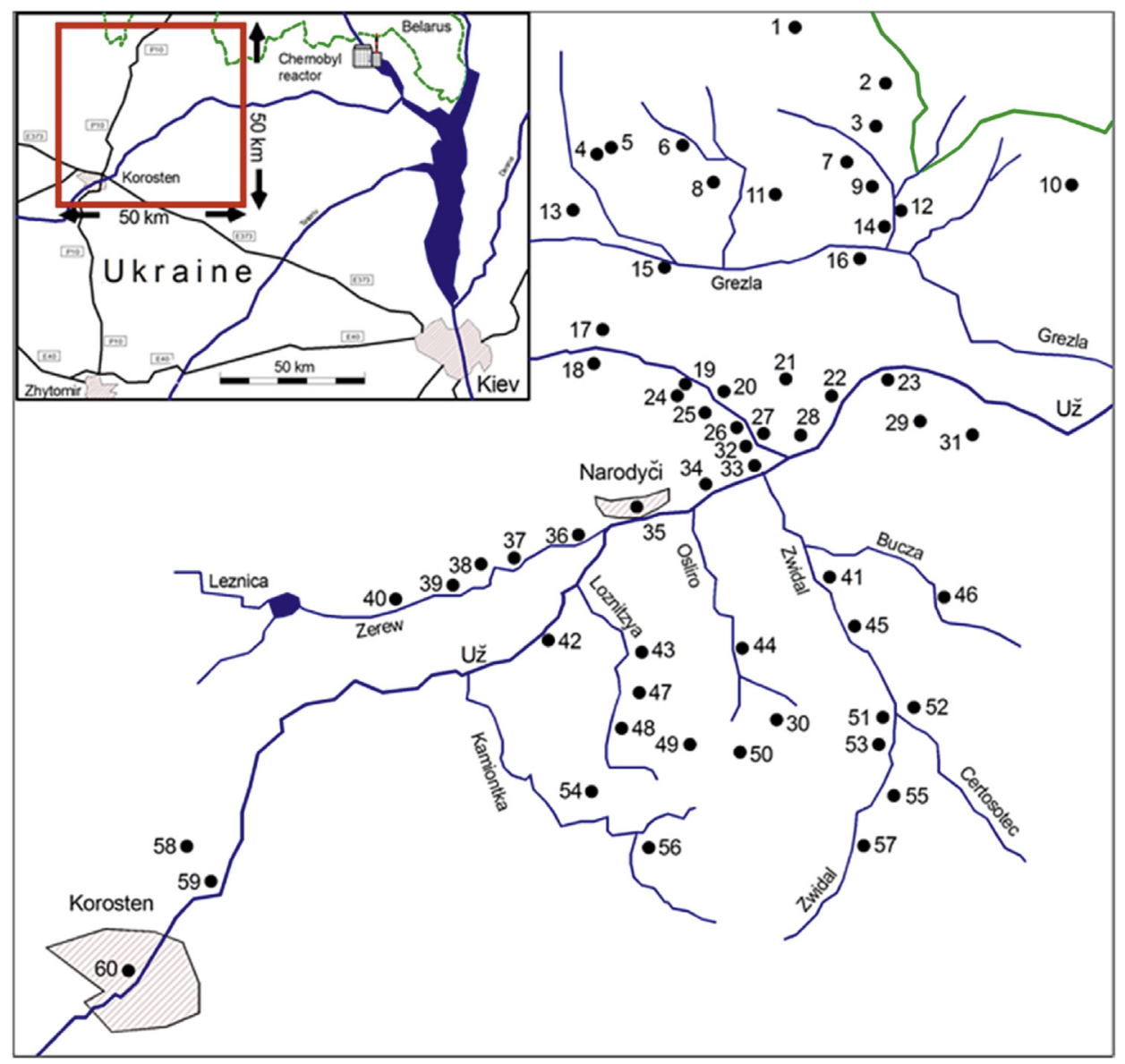

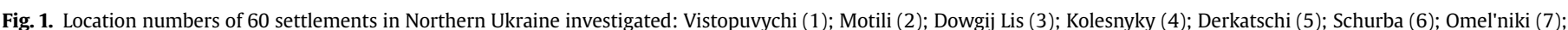

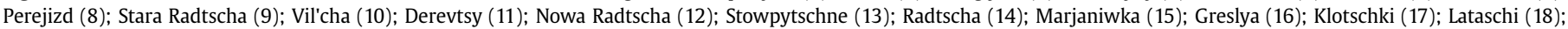

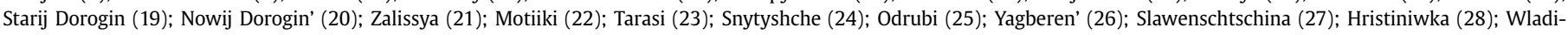

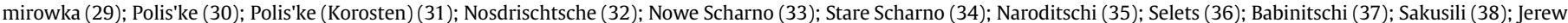

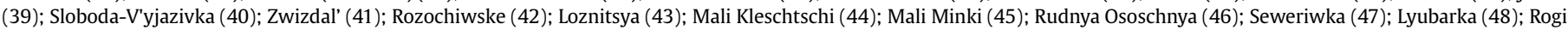

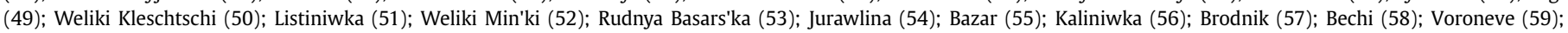
Korosten (60).

calculate proxies for the inventories in units of $\mathrm{g} \mathrm{m}^{-2}$ or $\mathrm{Bq} \mathrm{m}^{-2}$ according to Equation (1).

$D \approx A_{\mathrm{F}}\left(d_{\max }, 0\right)=\int_{d_{\max }}^{0} C(d) \cdot \rho(d) \mathrm{d} d$

with $d_{\max }$ being the maximum sampling depth, $C(d)$ the specific activity or mass concentration at depth $d$ of ${ }^{129} \mathrm{I},{ }^{137} \mathrm{Cs}$ and ${ }^{127} \mathrm{I}$, respectively, and $\rho(d)$ the bulk density of the air-dried soil at depth $d$.

The depth dependence of the inventories as a function of the upper integration boundaries, $d_{\min }$, according to Equation (2) are shown in Fig. 2.

$A_{\mathrm{F}}\left(d_{\max }, d_{\min }\right)=\int_{d_{\max }}^{d_{\min }} C(d) \cdot \rho(d) \mathrm{d} d$

Fig. 2 clearly shows the larger mobility of iodine compared to Caesium in the soils analysed. The inventories of ${ }^{127} \mathrm{I}$ are relatively low with values between $0.630 \mathrm{~g} \mathrm{~m}^{-2}$ and $2.4 \mathrm{~g} \mathrm{~m}^{-2}$ compared to ${ }^{127} \mathrm{I}$ in Western Europe where we observe values up to $7 \mathrm{~g} \mathrm{~m}^{-2}$ in Germany (Ernst et al., 2003; Michel et al., 2005; Schwinger, 2014). This observation can be understood by the North Sea and the North Atlantic, contaminated by the releases from the European reprocessing plants at La Hague and Sellafield, being the main sources of input of iodine into soils of Eastern Europe (Michel et al., 2012).

The discussion of the migration of ${ }^{127} \mathrm{I},{ }^{129} \mathrm{I}$ and ${ }^{137} \mathrm{Cs}$ in our earlier work (Michel et al., 2005) remains valid and shall not be repeated here. In summary, one concludes that a sampling depth of $40 \mathrm{~cm}$ appears to be sufficient to cover most of the recent fall-out of ${ }^{129}$ I and that the inventories in the sampled soil columns reveal the ${ }^{129}$ I deposition densities. But, in view of the results from Lower Saxony, Germany (Ernst et al., 2003), there remains a caveat. These data can only be regarded as lower limits of the total inventories. In spite of that, we shall use them as a proxy for the total inventories.

Fig. 3 shows the geometric means of the measured ${ }^{137} \mathrm{Cs}$ and ${ }^{129} \mathrm{I}$ inventories for 60 settlements superimposed on a map of Northern Ukraine. The measured ${ }^{137} \mathrm{Cs}$ and ${ }^{129} \mathrm{I}$ inventories were corrected for the pre-Chernobyl fall-out of ${ }^{129} \mathrm{I}$ and ${ }^{137} \mathrm{Cs}$ as described below. The geometric means of the corrected ${ }^{137} \mathrm{Cs}$ and ${ }^{129} \mathrm{I}$ inventories are given in Table 1 together with the geometric standard deviations derived from the 5 samples of each of the 60 settlements. Table 1 and Fig. 4 present the ${ }^{131}$ I inventories derived from the geometric means of the inventories corrected for the respective preChernobyl fall-out. The standard uncertainties given include the standard uncertainties of the pre-Chernobyl fall-out values.

While the data of ${ }^{4} \mathrm{~K}$ and ${ }^{127} \mathrm{I}$ in the individual settlements are 

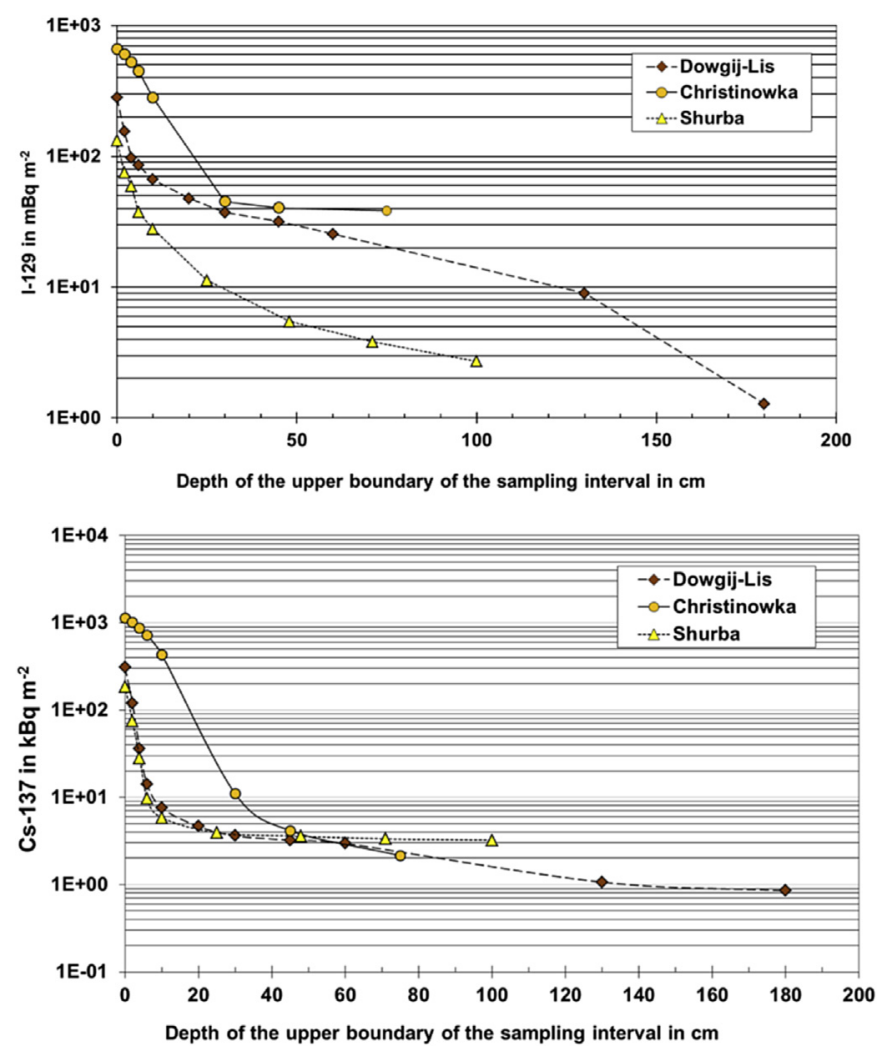

Fig. 2. Dependence of depth of the inventories of ${ }^{129} \mathrm{I}$ and ${ }^{137} \mathrm{Cs}$ (as of 2009).

quite homogeneous (Daraoui, 2010) the ${ }^{137}$ Cs and ${ }^{129}$ I show high variability.

In the area investigated, the fall-out of ${ }^{129} \mathrm{I},{ }^{131} \mathrm{I}$, and ${ }^{137} \mathrm{Cs}$ was extremely inhomogeneous and varied frequently by an order of magnitude from settlement to settlement (Figs. 3 and 4) and within the individual settlements (Fig 6). The large local variations of the fall-out are a well-known fact for Northern Ukraine where the first westerly plume traversed the country (Ministry of Ukraine, (2008)). Reasons for this variability are the particular orographic situation in particular the presence of forests or open fields or grassland and the differences of local wet and dry deposition.

The range of ${ }^{137} \mathrm{Cs}$ inventories (as of 1986) due to the Chernobyl accident of all individual samples was between $65 \mathrm{kBq} \mathrm{m}^{-2}$ and 10.3 $\mathrm{MBq} \mathrm{\textrm {m } ^ { - 2 }}$ in contamination zone II. The villages with the highest values were Wladimirowka (No. 29 in Fig. $1 ;\left(10.3 \times 1.9^{ \pm 1}\right)$ $\mathrm{MBq} \mathrm{m}{ }^{-2}$ ), Nowe Scharno (No. 33 in Fig. $1 ;\left(8.0 \times 1.6^{ \pm 1}\right) \mathrm{MBq} \mathrm{m}^{-2}$ ) and Stare Scharno (No. 34 in Fig. 1 ; $\left.\left(3.4 \times 2.1^{ \pm 1}\right) \mathrm{MBq} \mathrm{m}^{-2}\right)$. The lowest value was found in Weliki Min'ki (No. 52 in Fig. 1; $\left(65 \times 2.3^{ \pm 1}\right) \mathrm{kBq} \mathrm{m}{ }^{-2}$. In contamination zone III, the range of ${ }^{137} \mathrm{Cs}$ inventories due to the Chernobyl accident was from $38 \mathrm{kBq} \mathrm{m}^{-2}$ to $637 \mathrm{kBq} \mathrm{m}^{-2}$. The highest value was found in Voroneve (No. 59 in Fig. $\left.1 ;\left(637 \times 1.4^{ \pm 1}\right) \mathrm{kBq} \mathrm{m}^{-2}\right)$, the lowest one at Brodnik (No. 38 in Fig. $\left.1 ;\left(38 \times 1.6^{ \pm 1}\right) \mathrm{kBq} \mathrm{m}^{-2}\right)$.

For ${ }^{129} \mathrm{I}$, the corresponding data were between $14 \mathrm{mBq} \mathrm{m}^{-2}$ and $2.0 \mathrm{~Bq} \mathrm{~m}^{-2}$ in contamination zone II and in contamination zone III between $15 \mathrm{mBq} \mathrm{m}^{-2}$ and $117 \mathrm{mBq} \mathrm{m}^{-2}$. The highest ${ }^{129}$ I inventory was found at Wladimirowka (No. 29 in Fig. $1 ; 2.0 \times 2.0^{ \pm 1}$ ) Bq $\mathrm{m}^{-2}$ ), followed by Nowe Scharno (No. 33 in Fig. $1 ;\left(1.2 \times 2.0^{ \pm 1}\right) \mathrm{Bq} \mathrm{m}^{-2}$ ), Rudnya Ososchnya (No. 46 in Fig. $\left.1 ;\left(689 \times 2.5^{ \pm 1}\right) \mathrm{mBq} \mathrm{m}^{-2}\right)$, Mali Minki (No. 45 in Fig. $\left.1 ;\left(523 \times 2.1^{ \pm 1}\right) \mathrm{mBq} \mathrm{m}^{-2}\right)$, Zwisdal' (No. 41 in Fig. 1 ; $\left.\left(478 \times 1.4^{ \pm 1}\right) \mathrm{mBq} \mathrm{m}^{-2}\right)$ and Stare Scharno (No. 34 in Fig. 1; $\left.\left(371 \times 1.6^{ \pm 1}\right) \mathrm{mBq} \mathrm{m}^{-2}\right)$. The lowest ${ }^{129}$ I inventory in zone II was found in Omel'niki (No. 7 in Fig. 1 ; $\left.\left(14 \times 5.2^{ \pm 1}\right) \mathrm{mBq} \mathrm{m}^{-2}\right)$.
In contamination zone III the highest ${ }^{129}$ I inventory was found in Korosten (No. 60 in Fig. 1 ; $\left.\left(117 \times 4.8^{ \pm 1}\right) \mathrm{mBq} \mathrm{m}^{-2}\right)$, the lowest one in Lataschi (No. 18 in Fig. 1 ; $\left.\left(15 \times 2.3^{ \pm 1}\right) \mathrm{mBq} \mathrm{m}^{-2}\right)$.

Though the deposition pattern of ${ }^{137} \mathrm{Cs}$ and ${ }^{129} \mathrm{I}$ are in general agreement, they do not agree for the individual settlements as revealed by differing ratios of the mean ${ }^{129} \mathrm{I}$ and ${ }^{137} \mathrm{Cs}$ inventories. As a consequence, we will rely for the retrospective dosimetry on the ${ }^{129}$ I inventories since it avoids the problem of varying Iodine/ Caesium ratios.

The ${ }^{131}$ I deposition was calculated from the ${ }^{129}$ I inventories after correction for a pre-Chernobyl inventory of $(44 \pm 24) \mathrm{mBq} \mathrm{m}^{-2}$ assuming an ${ }^{131} \mathrm{I} /{ }^{129} \mathrm{I}$ activity ratio $A_{131} / A_{129}=(5.3 \pm 0.3) \times 10^{7}$ at the time of the accident: A discussion of the pre-Chernobyl inventory and of the ${ }^{131} \mathrm{I} /{ }^{129} \mathrm{I}$ activity ratio is given below. The calculated ${ }^{131} \mathrm{I}$ deposition ranges from $0.81 \mathrm{MBq} \mathrm{m}^{-2}$ to $120 \mathrm{MBq}$ $\mathrm{m}^{-2}$ in contamination zone II and from $0.9 \mathrm{MBq} \mathrm{m}^{-2}$ to $6.9 \mathrm{MBq}$ $\mathrm{m}^{-2}$ in contamination zone III (Table 1 and Fig. 4). Talerko (2005) calculated the highest integral ${ }^{131} \mathrm{I}$ deposition in the Zhitomir region for Nowe Scharno to be $28.6 \mathrm{MBq} \mathrm{m}^{-2}$. This observation is in general agreement with our findings, though our value is with $\left(73 \times 1.8^{ \pm 1}\right) \mathrm{MBq} \mathrm{m}^{-2}$ somewhat higher than that calculated by Talerko (2005). We find the highest ${ }^{131}$ I deposition in Wladimirowka (No. 29 in Fig. 1 ; $\left.\left(120 \times 2.0^{ \pm 1}\right) \mathrm{MBq} \mathrm{m}^{-2}\right)$ some $6 \mathrm{~km}$ ENE of Nowe Scharno.

According to our results, the highest ${ }^{131}$ I depositions occurred from Wladimirowka (29) up the river Už via Hristiniwka, Nowe Scharno to Stare Scharno and in an area south of the river Už along the rivers Swidal and Bucza (settlements 41, 45, and 46). The town Narodici (35) received a ${ }^{131}$ I deposition of just $3.3 \mathrm{MBq} \mathrm{m}^{-2}$ and to the west of Narodice the ${ }^{131}$ I depositions remained well below $5 \mathrm{MBq} \mathrm{m}{ }^{-2}$. The town of Korosten (69) and the neighbouring settlements $(58,59)$ again got a higher ${ }^{131} \mathrm{I}$ deposition of about $6 \mathrm{MBq} \mathrm{m}^{-2}$.

Our results show that a high variability did occur not only on a large scale between settlements but also on a much smaller scale within the individual settlements. The variability of the individual inventories determined is shown in Fig. 5 for ${ }^{137} \mathrm{Cs}$ and ${ }^{129} \mathrm{I}$, in Fig. 6 histograms of the geometric standard deviations are given. The geometric standard deviations show log-normal distributions. The modes of the distributions are between 1.5 and 2 for both nuclides. But, the distribution is broader in case of ${ }^{137} \mathrm{Cs}$ exhibiting a larger variability for this nuclide.

\section{The pre-Chernobyl fall-out of ${ }^{129}$ I and ${ }^{137}$ Cs}

For the retrospective dosimetry via ${ }^{129} \mathrm{I}$ or ${ }^{137} \mathrm{Cs}$ one needs reliable estimates of the inventories of the pre-Chernobyl fall-out of ${ }^{129} \mathrm{I}$ and ${ }^{137} \mathrm{Cs}, D_{\text {pre-Ch. }}\left({ }^{129} \mathrm{I}\right)$ and $D_{\text {pre-Ch. }}\left({ }^{137} \mathrm{Cs}\right)$, respectively. In the case of ${ }^{137} \mathrm{Cs}$ this is relatively simple since a large number of measurements of the weapon fall-out exist and since there is no other significant pre-Chernobyl source of this nuclide. The $D_{\text {pre-Ch. }}\left({ }^{137} \mathrm{Cs}\right)$ of $\left(4.8 \times 1.4^{ \pm 1}\right) \mathrm{kBq} \mathrm{m}^{-2}$ derived for Lower Saxony/Germany (Ernst et al., 2003) is also a good estimate for the pre-Chernobyl integral ${ }^{137}$ Cs inventory in Ukraine, Belarus and Russia as it is to be expected from the homogeneity of the global weapons fall-out. As discussed by Michel et al. $(2005)$ we assume $\left.D_{\text {pre-Ch. }}{ }^{137} \mathrm{Cs}\right)=\left(4.8 \times 1.4^{ \pm 1}\right) \mathrm{kBq}$ $\mathrm{m}^{-2}$; a value which is by far exceeded by all ${ }^{137} \mathrm{Cs}$ inventories determined in this work.

Also, the total inventories of ${ }^{129} \mathrm{I}$ are much higher than the ${ }^{129} \mathrm{I}$ inventories due to fall-out of atmospheric nuclear explosions in the northern hemisphere. Estimates of the weapons fall-out of ${ }^{129}$ I are $1.0 \mathrm{mBq} \mathrm{m}^{-2}$ (Daraoui et al., 2012), $1.4 \mathrm{mBq} \mathrm{m}^{-2}$ (Rao and Fehn, 1999) and $2.9 \mathrm{mBq} \mathrm{m}^{-2}$ (Oktay et al., 2000; Schink et al., 1995). However, in the case of ${ }^{129}$ I there are other man-made sources which contribute significantly in Europe namely the releases from 
Table 1

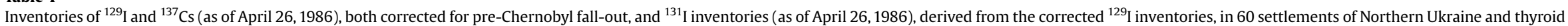
equivalent doses due to ${ }^{131} \mathrm{I}$ calculated from corrected ${ }^{129} \mathrm{I}$ and ${ }^{137} \mathrm{Cs}$ inventories.

\begin{tabular}{|c|c|c|c|c|c|c|c|c|c|c|c|c|c|}
\hline \multirow[b]{3}{*}{ Vistopuyychi } & \multirow[t]{2}{*}{$\begin{array}{l}\text { Contamination } \\
\text { zone }\end{array}$} & \multirow[t]{2}{*}{$\begin{array}{l}\text { Nr. in } \\
\text { Fig. } 1 .\end{array}$} & $\begin{array}{l}\text { Northern } \\
\text { latitude }\end{array}$ & $\begin{array}{l}\text { Eastern } \\
\text { longitude }\end{array}$ & \multirow{2}{*}{$\begin{array}{l}D\left({ }^{137} \mathrm{Cs}\right) \\
\text { in } \mathrm{kBq} \mathrm{m^{-2 }}\end{array}$} & \multirow{2}{*}{$\begin{array}{l}D\left({ }^{129} \mathrm{I}\right) \\
\text { in } \mathrm{mBq} \mathrm{m}^{-2}\end{array}$} & \multirow{2}{*}{$\begin{array}{l}D\left({ }^{131} \mathrm{I}\right) \\
\text { from } D\left({ }^{129} \mathrm{I}\right) \\
\text { in MBq } \mathrm{m}^{-2}\end{array}$} & \multicolumn{3}{|c|}{$\begin{array}{l}{ }^{131} \text { I thyroid equivalent doses in Gy derived from } \\
{ }^{129} \text { I inventories }\end{array}$} & \multicolumn{3}{|c|}{$\begin{array}{l}{ }^{131} \text { I thyroid equivalent doses in Gy derived from } \\
{ }^{137} \mathrm{Cs} \text { inventories }\end{array}$} \\
\hline & & & \multicolumn{2}{|c|}{ in decimal degrees } & & & & $\begin{array}{l}5 \text {-years-old } \\
\text { children }\end{array}$ & $\begin{array}{l}\text { 10-years-old } \\
\text { children }\end{array}$ & Adults & $\begin{array}{l}5 \text {-years-old } \\
\text { children }\end{array}$ & $\begin{array}{l}\text { 10-years-old } \\
\text { children }\end{array}$ & Adults \\
\hline & II & 1 & 51.567 & 29.075 & $456 \times 2.1^{ \pm 1}$ & $184 \times 2.1^{ \pm 1}$ & ${ }^{1} 10.9 \times 2.1^{ \pm 1}$ & $2.7 \times 2.1^{ \pm 1}$ & $1.8 \times 2.1^{ \pm 1}$ & $0.6 \times 2.1^{ \pm 1}$ & $1.6 \times 2.1^{ \pm 1}$ & $1.0 \times 2.1^{ \pm 1}$ & $0.7 \times 2.1^{ \pm 1}$ \\
\hline Motili & II & 2 & 51.432 & 29.272 & $193 \times 1.2^{ \pm 1}$ & $44 \times 2.8^{ \pm 1}$ & $1 \quad 2.6 \times 2.8^{ \pm 1}$ & $0.7 \times 2.8^{ \pm 1}$ & $0.4 \times 2.8^{ \pm 1}$ & $0.2 \times 2.8^{ \pm 1}$ & $0.7 \times 1.2^{ \pm 1}$ & $0.4 \times 1.2^{ \pm 1}$ & $0.3 \times 1.2^{ \pm 1}$ \\
\hline Dowgij Lis & II & 3 & 51.414 & 29.279 & $628 \times 1.7^{ \pm 1}$ & $228 \times 2.7^{ \pm 1}$ & $1 \quad 14 \times 2.7^{ \pm 1}$ & $3.4 \times 2.7^{ \pm 1}$ & $2.3 \times 2.7^{ \pm 1}$ & $0.8 \times 2.7^{ \pm 1}$ & $2.3 \times 1.7^{ \pm 1}$ & $1.4 \times 1.7^{ \pm 1}$ & $0.9 \times 1.7^{ \pm 1}$ \\
\hline Kolesnyky & II & 4 & 51.398 & 29.007 & $164 \times 1.4^{ \pm 1}$ & $46 \times 1.6^{ \pm 1}$ & $1 \quad 2.7 \times 1.6^{ \pm 1}$ & $0.7 \times 1.6^{ \pm 1}$ & $0.5 \times 1.6^{ \pm 1}$ & $0.2 \times 1.6^{ \pm 1}$ & $0.6 \times 1.4^{ \pm 1}$ & $0.4 \times 1.4^{ \pm 1}$ & $0.2 \times 1.4^{ \pm 1}$ \\
\hline Derkatschi & II & 5 & 51.406 & 29.043 & $390 \times 1.7^{ \pm 1}$ & $82 \times 1.6^{ \pm 1}$ & $14.9 \times 1.6^{ \pm 1}$ & $1.2 \times 1.6^{ \pm 1}$ & $0.8 \times 1.6^{ \pm 1}$ & $0.3 \times 1.6^{ \pm 1}$ & $1.4 \times 1.7^{ \pm 1}$ & $0.9 \times 1.7^{ \pm 1}$ & $0.6 \times 1.7^{ \pm 1}$ \\
\hline Schurba & II & 6 & 51.403 & 29.120 & $331 \times 4.9^{ \pm 1}$ & $128 \times 1.4^{ \pm 1}$ & $1 \quad 7.6 \times 1.4^{ \pm 1}$ & $1.9 \times 1.4^{ \pm 1}$ & $1.3 \times 1.4^{ \pm 1}$ & $0.5 \times 1.4^{ \pm 1}$ & $1.2 \times 4.9^{ \pm 1}$ & $0.8 \times 4.9^{ \pm 1}$ & $0.5 \times 4.9^{ \pm 1}$ \\
\hline Omel'niki & II & 7 & 51.391 & 29.248 & $218 \times 2.5^{ \pm 1}$ & $14 \times 5.2^{ \pm 1}$ & ${ }^{1} 0.81 \times 5.2^{ \pm 1}$ & $0.2 \times 5.2^{ \pm 1}$ & $0.1 \times 5.2^{ \pm 1}$ & $0.05 \times 5.2^{ \pm 1}$ & $0.8 \times 2.5^{ \pm 1}$ & $0.5 \times 2.5^{ \pm 1}$ & $0.3 \times 2.5^{ \pm 1}$ \\
\hline Perejizd & II & 8 & 51.379 & 29.140 & $102 \times 1.5^{ \pm 1}$ & $37 \times 1.9^{ \pm 1}$ & $1 \quad 2.2 \times 1.9^{ \pm 1}$ & $0.5 \times 1.9^{ \pm 1}$ & $0.4 \times 1.9^{ \pm 1}$ & $0.1 \times 1.9^{ \pm 1}$ & $0.4 \times 1.5^{ \pm 1}$ & $0.2 \times 1.5^{ \pm 1}$ & $0.2 \times 1.5^{ \pm 1}$ \\
\hline Stara Radtscha & III & 9 & 51.357 & 29.307 & $118 \times 2.0^{ \pm 1}$ & $54 \times 1.4^{ \pm 1}$ & $3.3 \times 1.5^{ \pm 1}$ & $0.8 \times 1.5^{ \pm 1}$ & $0.5 \times 1.5^{ \pm 1}$ & $0.2 \times 1.5^{ \pm 1}$ & $0.4 \times 2.0^{ \pm 1}$ & $0.3 \times 2.0^{ \pm 1}$ & $0.2 \times 2.0^{ \pm 1}$ \\
\hline Vil'cha & II & 10 & 51.370 & 29.420 & $163 \times 4.4^{ \pm 1}$ & $62 \times 4.0^{ \pm 1}$ & $2.5 \times 4.0^{ \pm 1}$ & $0.9 \times 4.0^{ \pm 1}$ & $0.6 \times 4.0^{ \pm 1}$ & $0.2 \times 4.0^{ \pm 1}$ & $0.6 \times 4.4^{ \pm 1}$ & $0.4 \times 4.4^{ \pm 1}$ & $0.2 \times 4.4^{ \pm 1}$ \\
\hline Derevtsy & II & 11 & 51.374 & 29.134 & $244 \times 1.2^{ \pm 1}$ & $105 \times 2.8^{ \pm 1}$ & $6.3 \times 2.8^{ \pm 1}$ & $1.6 \times 2.8^{ \pm 1}$ & $1.0 \times 2.8^{ \pm 1}$ & $0.4 \times 2.8^{ \pm 1}$ & $0.9 \times 1.2^{ \pm 1}$ & $0.6 \times 1.2^{ \pm 1}$ & $0.4 \times 1.2^{ \pm 1}$ \\
\hline Nowa Radtscha & III & 12 & 51.251 & 29.307 & $60 \times \times 3.3^{ \pm 1}$ & $42 \times 1.5^{ \pm 1}$ & $1 \quad 2.5 \times 1.5^{ \pm 1}$ & $0.6 \times 1.5^{ \pm 1}$ & $0.4 \times 1.5^{ \pm 1}$ & $0.1 \times 1.5^{ \pm 1}$ & $0.2 \times 3.3^{ \pm 1}$ & $0.1 \times 3.3^{ \pm 1}$ & $0.1 \times 3.3^{ \pm 1}$ \\
\hline Stowpytschne & II & 13 & 51.381 & 29.009 & $383 \times 1.5^{ \pm 1}$ & $85 \times 2.0^{ \pm 1}$ & $5.5 \times 2.1^{ \pm 1}$ & $1.4 \times 2.1^{ \pm 1}$ & $0.9 \times 2.1^{ \pm 1}$ & $0.3 \times 2.1^{ \pm 1}$ & $1.4 \times 1.5^{ \pm 1}$ & $0.9 \times 1.5^{ \pm 1}$ & $0.6 \times 1.5^{ \pm 1}$ \\
\hline Radtscha & III & 14 & 51.379 & 29.298 & $52 \times 2.6^{ \pm 1}$ & $31 \times 2.9^{ \pm 1}$ & $1.8 \times 2.9^{ \pm 1}$ & $0.5 \times 2.9^{ \pm 1}$ & $0.3 \times 2.9^{ \pm 1}$ & $0.1 \times 2.9^{ \pm 1}$ & $0.2 \times 2.6^{ \pm 1}$ & $0.1 \times 2.6^{ \pm 1}$ & $0.1 \times 2.6^{ \pm 1}$ \\
\hline Marjaniwka & III & 15 & 51.331 & 29.270 & $89 \times 2.6^{ \pm 1}$ & $33 \times 2.1^{ \pm 1}$ & $1 \quad 2.0 \times 2.1^{ \pm 1}$ & $0.5 \times 2.1^{ \pm 1}$ & $0.3 \times 2.1^{ \pm 1}$ & $0.1 \times 2.1^{ \pm 1}$ & $0.3 \times 2.6^{ \pm 1}$ & $0.2 \times 2.6^{ \pm 1}$ & $0.1 \times 2.6^{ \pm 1}$ \\
\hline Greslya & III & 16 & 51.353 & 29.284 & $68 \times 1.6^{ \pm 1}$ & $17 \times 4.9^{ \pm 1}$ & $1.0 \times 4.9^{ \pm 1}$ & $0.3 \times 4.9^{ \pm 1}$ & $0.2 \times 4.9^{ \pm 11}$ & $0.1 \times 4.9^{ \pm 1}$ & $0.2 \times 1.6^{ \pm 1}$ & $0.2 \times 1.6^{ \pm 1}$ & $0.1 \times 1.6^{ \pm 1}$ \\
\hline Klotschki & III & 17 & 51.326 & 29.087 & $111 \times 2.2^{ \pm 1}$ & $22 \times 3.9^{ \pm 1}$ & $1.3 \times 3.9^{ \pm 1}$ & $0.3 \times 3.9^{ \pm 1}$ & $0.2 \times 3.9^{ \pm 1}$ & $0.1 \times 3.9^{ \pm 1}$ & $0.4 \times 2.2^{ \pm 1}$ & $0.3 \times 2.2^{ \pm 1}$ & $0.2 \times 2.2^{ \pm 1}$ \\
\hline Lataschi & III & 18 & 51.295 & 29.043 & $71 \times 3.6^{ \pm 1}$ & $15 \times 2.3^{ \pm 1}$ & $0.9 \times 2.2^{ \pm 1}$ & $0.2 \times 2.2^{ \pm 1}$ & $0.1 \times 2.2^{ \pm 1}$ & $0.1 \times 2.2^{ \pm 1}$ & $0.3 \times 3.6^{ \pm 1}$ & $0.2 \times 3.6^{ \pm 1}$ & $0.1 \times 3.6^{ \pm 1}$ \\
\hline Starij Dorogin & III & 19 & 51.257 & 29.154 & $137 \times 3.9^{ \pm 1}$ & $114 \times 4.3^{ \pm 1}$ & $6.8 \times 4.3^{ \pm 1}$ & $1.7 \times 4.3^{ \pm 1}$ & $1.1 \times 4.3^{ \pm 1}$ & $0.4 \times 4.3^{ \pm 1}$ & $0.5 \times 3.9^{ \pm 1}$ & $0.3 \times 3.9^{ \pm 1}$ & $0.2 \times 3.9^{ \pm 1}$ \\
\hline Nowij Dorogin' & III & 20 & 51.268 & 29.209 & $228 \times 1.7^{ \pm 1}$ & $36 \times 4.9^{ \pm 1}$ & $2.1 \times 4.9^{ \pm 1}$ & $0.5 \times 4.9^{ \pm 1}$ & $0.4 \times 4.9^{ \pm 1}$ & $0.1 \times 4.9^{ \pm 1}$ & $0.8 \times 1.7^{ \pm 1}$ & $0.5 \times 1.7^{ \pm 1}$ & $0.3 \times 1.7^{ \pm 1}$ \\
\hline Zalissya & III & 21 & 51.264 & 29.242 & $465 \times 1.5^{ \pm 1}$ & $91 \times 2.4^{ \pm 1}$ & $5.4 \times 2.4^{ \pm 1}$ & $1.3 \times 2.4^{ \pm 1}$ & $0.9 \times 2.4^{ \pm 1}$ & $0.3 \times 2.4^{ \pm 1}$ & $1.7 \times 1.5^{ \pm 1}$ & $1.1 \times 1.5^{ \pm 1}$ & $0.7 \times 1.5^{ \pm 1}$ \\
\hline Motiiki & III & 22 & 51.261 & 29.114 & $398 \times 1.7^{ \pm 1}$ & $65 \times 1.2^{ \pm 1}$ & $13.9 \times 1.2^{ \pm 1}$ & $1.0 \times 1.2^{ \pm 1}$ & $0.6 \times 1.2^{ \pm 1}$ & $0.2 \times 1.2^{ \pm 1}$ & $1.4 \times 1.7^{ \pm 1}$ & $0.9 \times 1.7^{ \pm 1}$ & $0.6 \times 1.7^{ \pm 1}$ \\
\hline Tarasi & II & 23 & 51.259 & 29.308 & $424 \times 1.1^{ \pm 1}$ & $86 \times 1.3^{ \pm 1}$ & $15.1 \times 1.3^{ \pm 1}$ & $1.3 \times 1.3^{ \pm 1}$ & $0.9 \times 1.3^{ \pm 1}$ & $0.3 \times 1.3^{ \pm 1}$ & $1.5 \times 1.1^{ \pm 1}$ & $1.0 \times 1.1^{ \pm 1}$ & $0.6 \times 1.1^{ \pm 1}$ \\
\hline Snytyshche & III & 24 & 51.274 & 29.037 & $175 \times 1.2^{ \pm 1}$ & $46 \times 1.3^{ \pm 1}$ & $12.7 \times 1.3^{ \pm 1}$ & $0.7 \times 1.3^{ \pm 1}$ & $0.5 \times 1.3^{ \pm 1}$ & $0.2 \times 1.3^{ \pm 1}$ & $0.6 \times 1.2^{ \pm 1}$ & $0.4 \times 1.2^{ \pm 1}$ & $0.3 \times 1.2^{ \pm 1}$ \\
\hline Odrubi & III & 25 & 51.272 & 29.127 & $357 \times 1.1^{ \pm 1}$ & $100 \times 1.2^{ \pm 1}$ & $15.9 \times 1.2^{ \pm 1}$ & $1.5 \times 1.2^{ \pm 1}$ & $1.0 \times 1.2^{ \pm 1}$ & $0.4 \times 1.2^{ \pm 1}$ & $1.3 \times 1.1^{ \pm 1}$ & $0.8 \times 1.1^{ \pm 1}$ & $0.5 \times 1.1^{ \pm 1}$ \\
\hline Yagberen' & III & 26 & 51.272 & 29.127 & $157 \times 2.7^{ \pm 1}$ & $89 \times 1.5^{ \pm 1}$ & $15.3 \times 1.5^{ \pm 1}$ & $1.3 \times 1.5^{ \pm 1}$ & $0.9 \times 1.5^{ \pm 1}$ & $0.3 \times 1.5^{ \pm 1}$ & $0.6 \times 2.7^{ \pm 1}$ & $0.4 \times 2.7^{ \pm 1}$ & $0.2 \times 2.7^{ \pm 1}$ \\
\hline Slawenschtschina & a III & 27 & 51.076 & 29.265 & $273 \times 1.9^{ \pm 1}$ & $78 \times 4.1^{ \pm 1}$ & $14.6 \times 4.1^{ \pm 1}$ & $1.1 \times 4.1^{ \pm 1}$ & $0.8 \times 4.1$ & $0.3 \times 5.1^{ \pm 1}$ & $1.0 \times 1.9^{ \pm 1}$ & $0.6 \times 1.9^{ \pm 1}$ & $0.4 \times 1.9^{ \pm 1}$ \\
\hline Hristiniwka & II & 28 & 51.241 & 29.208 & $1020 \times 5.6^{ \pm 1}$ & $214 \times 4,3^{ \pm 1}$ & $18.0 \times 4.3^{ \pm 1}$ & $2.0 \times 4.3^{ \pm 1}$ & $1.3 \times 4.3^{ \pm 1}$ & $0.5 \times 4.3^{ \pm 1}$ & $3.7 \times 5.6^{ \pm 1}$ & $2.3 \times 5.6^{ \pm 1}$ & $1.5 \times 5.6^{ \pm 1}$ \\
\hline Wladimirowka & II & 29 & 51.230 & 29.303 & $10,326 \times 1.9^{ \pm 1}$ & $2007 \times 2.0^{ \pm 1}$ & $120 \times 2.0^{ \pm 1}$ & $30 \times 2.0^{ \pm 1}$ & $20 \times 2.0^{ \pm 1}$ & $7.1 \times 2.0^{ \pm 1}$ & $37 \times 1.9^{ \pm 1}$ & $24 \times 1.9^{ \pm 1}$ & $16 \times 1.9^{ \pm 1}$ \\
\hline Polis'ke & II & 30 & 51.086 & 29.205 & $925 \times 2.3^{ \pm 1}$ & $95 \times 2.9^{ \pm 1}$ & $5.7 \times 2.9^{ \pm 1}$ & $1.4 \times 2.9^{ \pm 1}$ & $0.9 \times 2.9^{ \pm 1}$ & $0.3 \times 2.9^{ \pm 1}$ & $3.3 \times 2.3^{ \pm 1}$ & $2.1 \times 2.3^{ \pm 1}$ & $1.4 \times 2.3^{ \pm 1}$ \\
\hline $\begin{array}{l}\text { Polis'ke } \\
\quad \text { (Korosten) }\end{array}$ & III & 31 & 51.015 & 29.275 & $310 \times 3.1^{ \pm 1}$ & $115 \times 2.1^{ \pm 1}$ & $6.8 \times 2.1^{ \pm 1}$ & $1.7 \times 2.1^{ \pm 1}$ & $1.1 \times 2.1$ & $0.4 \times 2.1^{ \pm 1}$ & $1.1 \times 3.1^{ \pm 1}$ & $0.7 \times 3.1^{ \pm 1}$ & $0.5 \times 3.1^{ \pm 1}$ \\
\hline Nosdrischtsche & II & 32 & 51.240 & 29.181 & $1238 \times 4.7^{ \pm 1}$ & $321 \times 2.8^{ \pm 1}$ & $19 \times 2.8^{ \pm 1}$ & $4.7 \times 2.8^{ \pm 1}$ & $3.2 \times 2.8^{ \pm 1}$ & $1.1 \times 2.8^{ \pm 1}$ & $4.5 \times 4.7^{ \pm 1}$ & $2.8 \times 4.7^{ \pm 1}$ & $1.9 \times 4.7^{ \pm 1}$ \\
\hline Nowe Scharno & II & 33 & 51.230 & 29.187 & $8022 \times 1.6^{ \pm 1}$ & $1231 \times 1.8^{ \pm 1}$ & $73 \times 1.8^{ \pm 1}$ & $18 \times 1.8^{ \pm 1}$ & $12 \times 1.8^{ \pm 1}$ & $4.3 \times 1.8^{ \pm 1}$ & $29 \times 1.6^{ \pm 1}$ & $19 \times 1.6^{ \pm 1}$ & $12 \times 1.6^{ \pm 1}$ \\
\hline Stare Scharno & II & 34 & 51.216 & 29.152 & $3444 \times 2.1^{ \pm 1}$ & $371 \times 1.6^{ \pm 1}$ & $1 \quad 22 \times 1.6^{ \pm 1}$ & $5.5 \times 1.6^{ \pm 1}$ & $3.7 \times 1.6^{ \pm 1}$ & $1.3 \times 1.6^{ \pm 1}$ & $12.4 \times 2.1^{ \pm 1}$ & $7.9 \times 2.1^{ \pm 1}$ & $5.2 \times 2.1^{ \pm 1}$ \\
\hline Naroditschi & II & 35 & 51.211 & 29.087 & $212 \times 2.5^{ \pm 1}$ & $55 \times 2.6^{ \pm 1}$ & $13.3 \times 2.6^{ \pm 1}$ & $0.8 \times 2.6^{ \pm 1}$ & $0.6 \times 2.6^{ \pm 1}$ & $0.2 \times 2.6^{ \pm 1}$ & $0.8 \times 2.5^{ \pm 1}$ & $0.5 \times 2.5^{ \pm 1}$ & $0.3 \times 2.5^{ \pm 1}$ \\
\hline Selets & II & 36 & 51.187 & 29.031 & $545 \times 1.8^{ \pm 1}$ & $74 \times 2.0^{ \pm 1}$ & $4.4 \times 2.0^{ \pm 1}$ & $1.1 \times 2.0^{ \pm 1}$ & $0.7 \times 2.0^{ \pm 1}$ & $0.3 \times 2.0^{ \pm 1}$ & $2.0 \times 1.8^{ \pm 1}$ & $1.3 \times 1.8^{ \pm 1}$ & $0.8 \times 1.8^{ \pm 1}$ \\
\hline Babinitschi & III & 37 & 51.165 & 28.949 & $165 \times 1.6^{ \pm 1}$ & $44 \times 2.6^{ \pm 1}$ & $1 \quad 2.6 \times 2.6^{ \pm 1}$ & $0.6 \times 2.6^{ \pm 1}$ & $0.4 \times 2.6^{ \pm 1}$ & $0.2 \times 2.6^{ \pm 1}$ & $0.6 \times 1.6^{ \pm 1}$ & $0.4 \times 1.6^{ \pm 1}$ & $0.2 \times 1.6^{ \pm 1}$ \\
\hline Sakusili & III & 38 & 51.155 & 28.872 & $142 \times 1.9^{ \pm 1}$ & $54 \times 2.8^{ \pm 1}$ & $13.2 \times 2.8^{ \pm 1}$ & $0.8 \times 2.8^{ \pm 1}$ & $0.5 \times 2.8^{ \pm 1}$ & $0.2 \times 2.8^{ \pm 1}$ & $0.5 \times 1.9^{ \pm 1}$ & $0.3 \times 1.9^{ \pm 1}$ & $0.2 \times 1.9^{ \pm 1}$ \\
\hline Jerew & III & 39 & 51.173 & 28.980 & $138 \times 2.2^{ \pm 1}$ & $73 \times 1.2^{ \pm 1}$ & $4.4 \times 1.2^{ \pm 1}$ & $1.1 \times 1.2^{ \pm 1}$ & $0.7 \times 1.2^{ \pm 1}$ & $0.3 \times 1.2^{ \pm 1}$ & $0.5 \times 2.2^{ \pm 1}$ & $0.3 \times 2.2^{ \pm 1}$ & $0.2 \times 2.2^{ \pm 1}$ \\
\hline $\begin{array}{l}\text { Sloboda- } \\
\text { V'yjazivka }\end{array}$ & III & 40 & 51.261 & 29.080 & $137 \times 4.6^{ \pm 1}$ & $54 \times 4.4^{ \pm 1}$ & $3.2 \times 4.4^{ \pm 1}$ & $0.8 \times 4.4^{ \pm 1}$ & $0.5 \times 4.4^{ \pm 1}$ & $0.2 \times 4.4^{ \pm 1}$ & $0.5 \times 4.6^{ \pm 1}$ & $0.3 \times 4.6^{ \pm 1}$ & $0.2 \times 4.6^{ \pm 1}$ \\
\hline Zwizdal' & II & 41 & 51.173 & 29.244 & $1143 \times 3.4^{ \pm 1}$ & $478 \times 1.4^{ \pm 1}$ & $29 \times 1.4^{ \pm 1}$ & $7.0 \times 1.4^{ \pm 1}$ & $4.8 \times 1.4^{ \pm 1}$ & $1.7 \times 1.4^{ \pm 1}$ & $4.1 \times 3.4^{ \pm 1}$ & $2.6 \times 3.4^{ \pm 1}$ & $1.7 \times 3.4^{ \pm 1}$ \\
\hline Rozochiwske & II & 42 & 51.129 & 29.012 & $242 \times 6.0^{ \pm 1}$ & $92 \times 1.9^{ \pm 1}$ & $5.5 \times 1.9^{ \pm 1}$ & $1.4 \times 1.9^{ \pm 1}$ & $0.9 \times 1.9^{ \pm 1}$ & $0.3 \times 1.9^{ \pm 1}$ & $0.9 \times 6.0^{ \pm 1}$ & $0.6 \times 6.0^{ \pm 1}$ & $0.4 \times 6.0^{ \pm 1}$ \\
\hline Loznitsya & II & 43 & 51.124 & 29.088 & $592 \times 2.2^{ \pm 1}$ & $134 \times 1.7^{ \pm 1}$ & $8.0 \times 1.7^{ \pm 1}$ & $2.0 \times 1.7^{ \pm 1}$ & $1.3 \times 1.7^{ \pm 1}$ & $0.5 \times 1.7^{ \pm 1}$ & $2.1 \times 2.2^{ \pm 1}$ & $1.4 \times 2.2^{ \pm 1}$ & $0.9 \times 2.2^{ \pm 1}$ \\
\hline Mali Kleschtschi & II & 44 & 51.124 & 29.162 & $1206 \times 1.6^{ \pm 1}$ & $276 \times 1.6^{ \pm 1}$ & $16 \times 1.6^{ \pm 1}$ & $4.1 \times 1.6^{ \pm 1}$ & $2.7 \times 1.6^{ \pm 1}$ & $1.0 \times 1.6^{ \pm 1}$ & $4.3 \times 1.6^{ \pm 1}$ & $2.8 \times 1.6^{ \pm 1}$ & $1.8 \times 1.6^{ \pm 1}$ \\
\hline Mali Minki & II & 45 & 51.139 & 29.272 & $1580 \times 1.9^{ \pm 1}$ & $523 \times 2.1^{ \pm 1}$ & $31 \times 2.1^{ \pm 1}$ & $7.7 \times 2.1^{ \pm 1}$ & $5.2 \times 2.1^{ \pm 1}$ & $1.8 \times 2.1^{ \pm 1}$ & $5.7 \times 1.9^{ \pm 1}$ & $3.6 \times 1.9^{ \pm 1}$ & $2.4 \times 1.9^{ \pm 1}$ \\
\hline $\begin{array}{l}\text { Rudnya } \\
\text { Ososchnya }\end{array}$ & II & 46 & 51.150 & 29.352 & $2749 \times 3.0^{ \pm 1}$ & $689 \times 2.5^{ \pm 1}$ & $41 \times 2.5^{ \pm 1}$ & $10 \times 2.5^{ \pm 1}$ & $6.8 \times 2.5^{ \pm 1}$ & $2.4 \times 2.5^{ \pm 1}$ & $9.9 \times 3.0^{ \pm 1}$ & $6.3 \times 3.0^{ \pm 1}$ & $4.1 \times 3.0^{ \pm 1}$ \\
\hline Seweriwka & II & 47 & 51.104 & 29.073 & $260 \times 2.7^{ \pm 1}$ & $73 \times 2.4^{ \pm 1}$ & $4.4 \times 2.4^{ \pm 1}$ & $1.1 \times 2.4^{ \pm 1}$ & $0.7 \times 2.4^{ \pm 1}$ & $0.3 \times 2.4^{ \pm 1}$ & $0.9 \times 2.7^{ \pm 1}$ & $0.6 \times 2.7^{ \pm 1}$ & $0.4 \times 2.7^{ \pm 1}$ \\
\hline Lyubarka & II & 48 & 51.078 & 29.065 & $803 \times 1.6^{ \pm 1}$ & $175 \times 2.0^{ \pm 1}$ & $10 \times 2.0^{ \pm 1}$ & $2.6 \times 2.0^{ \pm 1}$ & $1.7 \times 2.0^{ \pm 1}$ & $0.6 \times 2.0^{ \pm 1}$ & $2.9 \times 1.6^{ \pm 1}$ & $1.8 \times 1.6^{ \pm 1}$ & $1.2 \times 1.6^{ \pm 1}$ \\
\hline
\end{tabular}




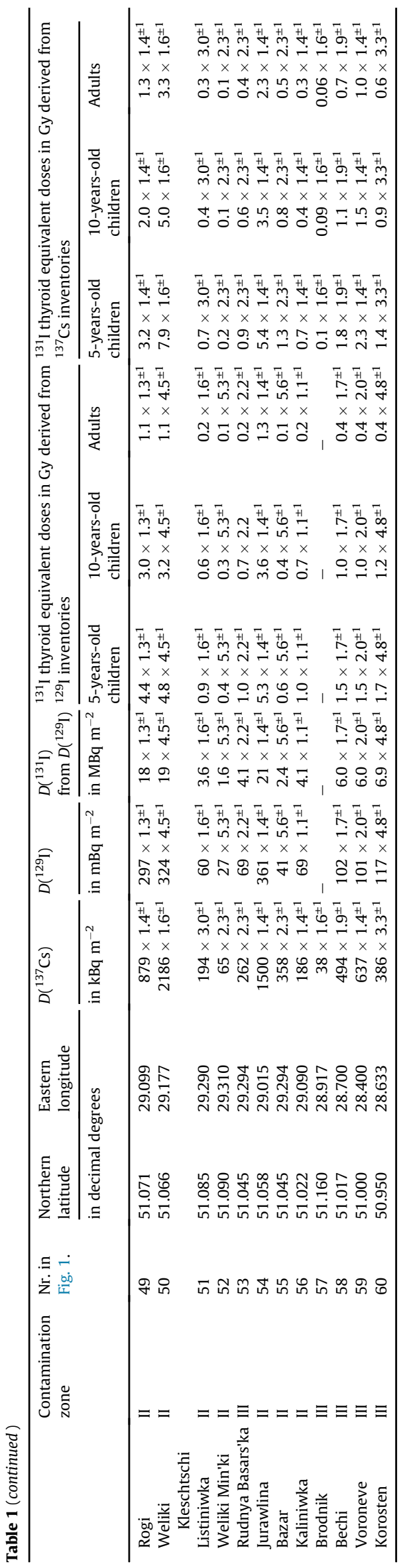

the European reprocessing plants; e.g. (Michel et al., 2012) and references therein. As discussed at length in our previous work (Michel et al., 2005), the contribution from the European reprocessing plants to the ${ }^{129}$ I contamination in Northern Ukraine was estimated from measured data for Moscow and for parts of the Zhitomir district which was not affected by the Chernobyl fall-out resulting in a best estimate for the pre-Chernobyl total inventory of ${ }^{129} \mathrm{I}$ of $(44 \pm 24) \mathrm{mBq} \mathrm{m}^{-2}$. This value of $D_{\text {pre-Ch. }}\left({ }^{129} \mathrm{I}\right)=(44 \pm 24)$ $\mathrm{mBq} \mathrm{m^{-2 }}$, used also in this work, is much higher than that estimated for the global weapons fall-out inventory of ${ }^{129}$ I. Thus, it turns out that also in Eastern Europe a substantial amount of ${ }^{129} \mathrm{I}$ from emissions from reprocessing plants has been deposited.

For Eastern Europe just a few other estimates of the preChernobyl inventories exist (Straume et al., 1996; Reithmeier et al., 2002; Mironov et al., 1999, 2002). Robl et al. (1997) and Pietrzak-Flis et al. (2003) assumed the same pre-Chernobyl contribution to ${ }^{129}$ I as Straume et al. (1996). They were discussed in detail in our earlier work (Michel et al., 2005). Here, we repeat some of this discussion regarding the works of Mironov et al. (1999, 2002) and Straume et al. (1996) and extend the discussion to the work of Straume et al. (2006).

Mironov et al. $(1999,2002)$ used values of $D_{\text {pre-Ch. }}\left({ }^{129} \mathrm{I}\right)=26$ $\mathrm{mBq} \mathrm{m}{ }^{-2}$ and $D_{\text {pre-Ch. }}\left({ }^{137} \mathrm{Cs}\right)=(2.4 \pm 0.6) \mathrm{kBq} \mathrm{m}^{-2}$. These values were derived from repeated analyses of an individual soil sample taken $400 \mathrm{~km}$ away from Chernobyl before the Chernobyl accident in 1985. They assumed a maximum penetration depth of the preChernobyl ${ }^{129}$ I of $20 \mathrm{~cm}$. An uncertainty of the value for ${ }^{129}$ I was not given; just the uncertainty of the repeated measurements of the ${ }^{129}$ I concentration of the sample (relative uncertainty of $15 \%$ ) was quoted. Also in the case of ${ }^{137} \mathrm{Cs}$ the quoted uncertainty refers only to the measurement uncertainty revealed by the repeated analyses of a single sample. The variability expected in different samples of the pre-Chernobyl fall-out was not estimated both for ${ }^{129}$ I and ${ }^{137}$ Cs. The authors noted that the pre-Chernobyl fall-out of ${ }^{129}$ I can only be explained by an additional source of ${ }^{129}$ I aside from global weapons fall-out.

Straume et al. (1996) based their pre-Chernobyl deposition estimate on the analysis of a soil sample from the San Joaquin Valley in California, USA with $6 \times 10^{7}{ }^{129} \mathrm{I}$ atoms per gram. Assuming an integration depth of $30 \mathrm{~cm}$ and a soil density of $1.5 \mathrm{~g} \mathrm{~cm}^{-3}$ this yields a value $D_{\text {pre-Ch. }}\left({ }^{129} \mathrm{I}\right)=26 \mathrm{mBq} \mathrm{m}^{-2}$. As pointed out by Michel et al. (2005) "the relative good agreement with our estimate appears to be accidental, since neither the latitude dependence of the atmospheric weapons fall-out was considered nor the even more important influence of emissions from reprocessing plants which are different in Europe and in North America."

Straume et al. (2006) assumed a pre-Chernobyl ${ }^{129}$ I fall-out of $(1.0 \pm 0.3) \times 10^{13}$ atoms per square meter and a pre-Chernobyl ${ }^{137} \mathrm{Cs}$ fall-out of $(2.0 \pm 0.7) \times 10^{12}$ atoms per square meter. These data correspond to $D_{\text {pre-Ch. }}\left({ }^{129} \mathrm{I}\right)=(14 \pm 4) \mathrm{mBq} \mathrm{m}^{-2}$ and $D_{\text {pre-Ch. }}\left({ }^{137} \mathrm{Cs}\right)=$ $(1.5 \pm 0.5) \mathrm{kBq} \mathrm{m}^{-2}$. These estimates were based on the results of measurements of samples from Belarus which exhibited low impact of the Chernobyl accident; see Fig. 4 in Straume et al. (2006). Two arguments were used. First, it was argued that the lowest inventories could provide an estimate of the pre-Chernobyl fall-out for both radionuclides. Second, assuming that the Chernobyl fallout was still retained in the upper $15 \mathrm{~cm}$ of the soil profiles it was argued that the inventories in a depth range of $15 \mathrm{~cm}-30 \mathrm{~cm}$ provide a lower limit of the pre-Chernobyl inventories and that it should be between this lower limit and the total inventories. This second argument appears, however, to be weak since also the inventories in the depth range $15 \mathrm{~cm}-30 \mathrm{~cm}$ increase with increasing Chernobyl impact. But even for the lowest inventories it cannot be assumed that pre-Chernobyl fall-out is not retained in the upper soil layers. While for ${ }^{137} \mathrm{Cs}$ the pre-Chernobyl fall-out occurred in 

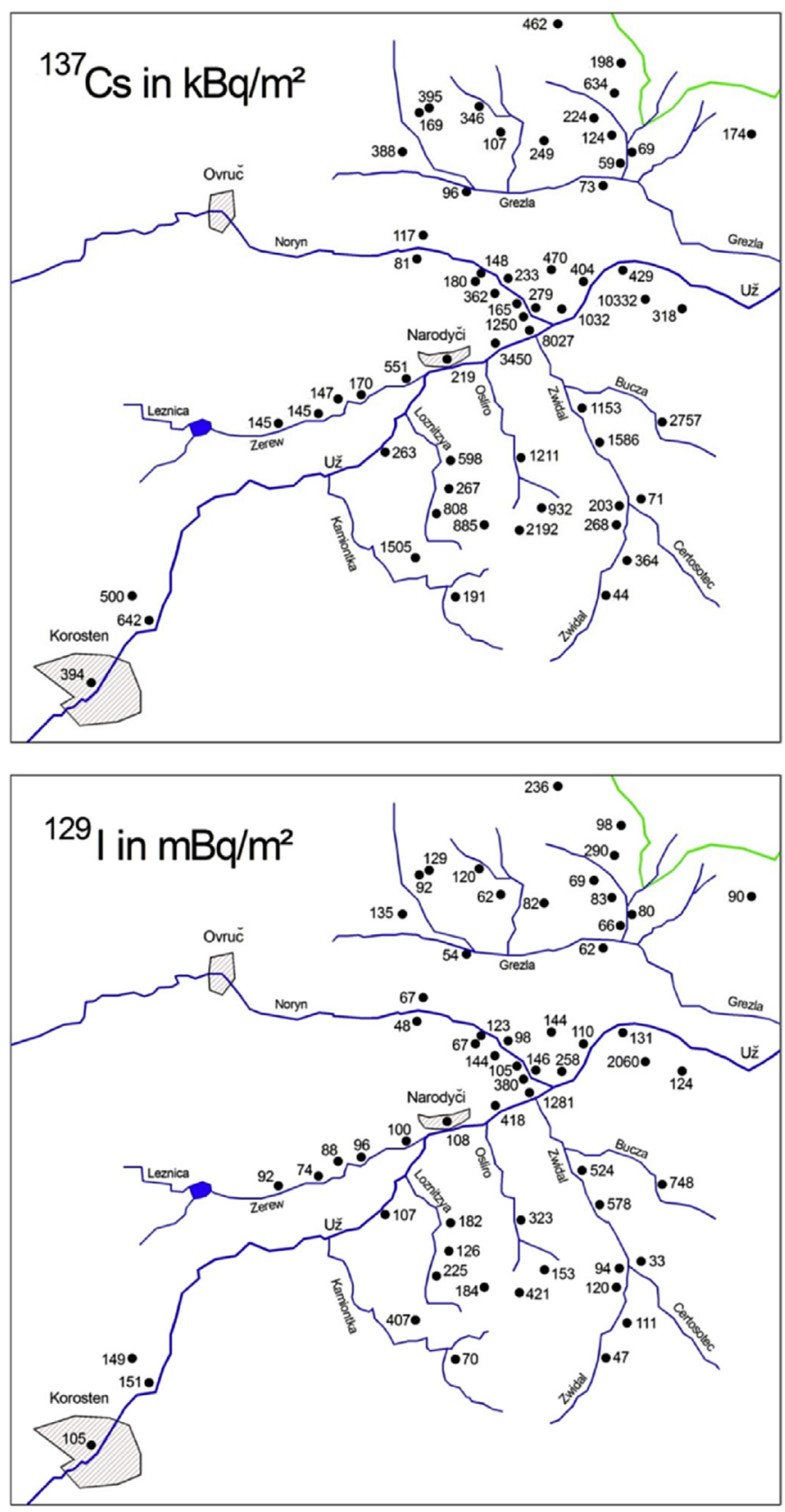

Fig. 3. Measured inventories of ${ }^{137} \mathrm{Cs}$ as of 26.4 .1986 (top) and of ${ }^{129} \mathrm{I}$ (bottom) of 60 settlements in Northern Ukraine investigated: the deposition data are the geometric means of the inventories measured in 5 samples of each settlement. The data are not corrected for the pre-Chernobyl fall-out of ${ }^{129} \mathrm{I}$ and ${ }^{137} \mathrm{Cs}$.

the 1950s and 1960s, the pre-Chernobyl ${ }^{129}$ I fall-out in Western Europe increased form the 1960s until 1986 by an order of magnitude and continued to increase thereafter (Michel et al., 2012). Thus, we conclude that the total inventories determined by Straume et al. (2006) for samples with low impact of the Chernobyl accident provide a better basis for the estimation of the preChernobyl inventory of ${ }^{129}$ I. From the data in Fig. 4 of Straume et al. (2006) a pre-Chernobyl ${ }^{129}$ I inventory can easily be derived which would be a factor of two higher that given by Straume et al. (2006) and which would be in reasonable agreement with our estimate considering the uncertainties induced by the variability of different samples.

For ${ }^{137} \mathrm{Cs}$, the pre-Chernobyl inventories can also be calculated

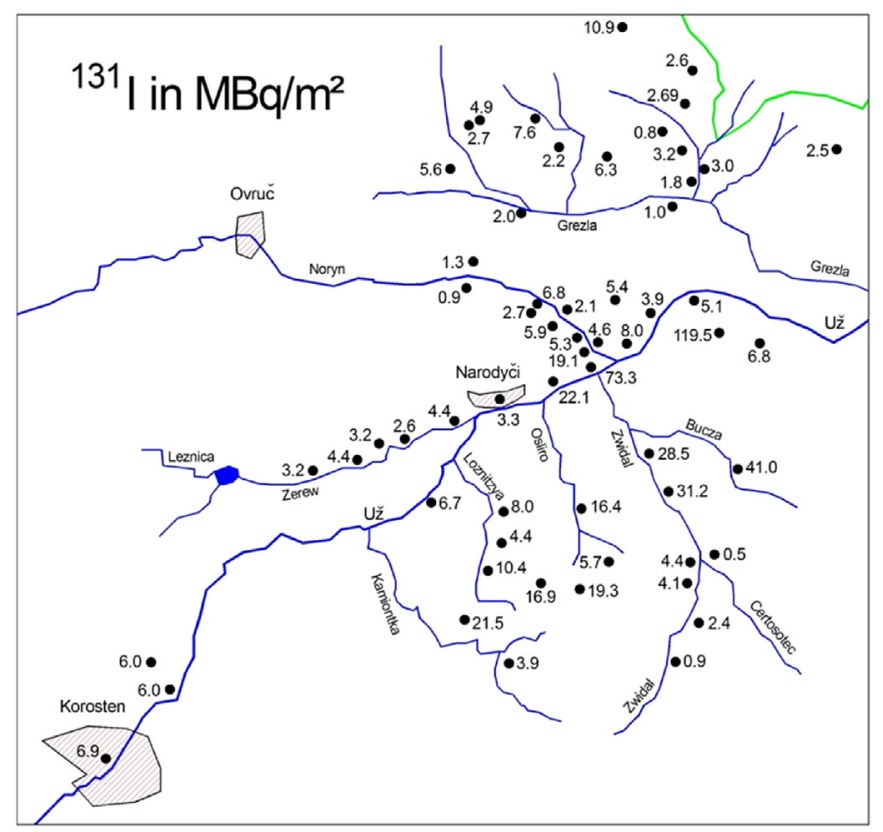

Fig. 4. Inventories of ${ }^{131} \mathrm{I}$ as of 26.4 .1986 of 60 settlements in Northern Ukraine calculated from the geometric means of five measured ${ }^{129} \mathrm{I}$ inventories in each settlement corrected for a pre-Chernobyl fall-out of $\left.{ }^{129} \mathrm{I} D_{\text {pre-Ch. }}{ }^{(29} \mathrm{I}\right)=44 \mathrm{mBq} \mathrm{m}^{-2}$.

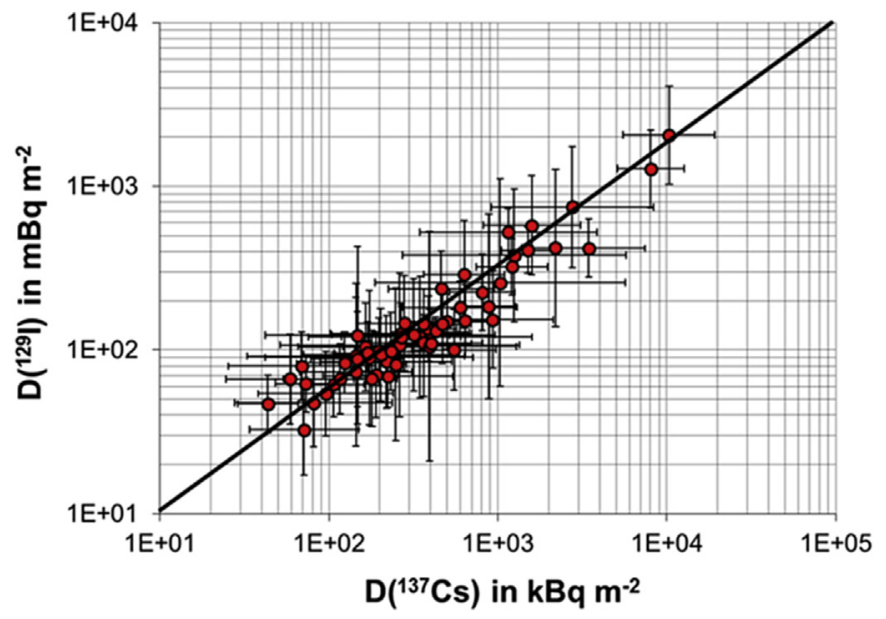

Fig. 5. Correlation between the measured ${ }^{129} \mathrm{I}$ and ${ }^{137} \mathrm{Cs}$ inventories in 1986 for 60 settlements in Northern Ukraine corrected for the pre-Chernobyl fall-out. The data points are logarithmic means and the uncertainties geometric standard deviations revealing the variability of the individual inventories derived from the five samples at each village. The data are highly correlated $D\left({ }^{129} \mathrm{I}\right)=0.18 \times D\left({ }^{137} \mathrm{Cs}\right)+67.2 \mathrm{mBq} \mathrm{m}^{-2}$ with $\mathrm{R}^{2}=0.9392$. In accordance with Michel et al. (2005) pre-Chernobyl inventories $D_{\text {pre-Ch. }}\left({ }^{129} \mathrm{I}\right)=(44 \pm 24) \mathrm{mBq} \mathrm{m}^{-2}$ and of $D_{\text {pre-Ch. }}\left({ }^{137} \mathrm{Cs}\right)$ of $\left(4.8 \times 1.4^{ \pm 1}\right) \mathrm{kBq} \mathrm{m^{-2 }}$ are assumed in this work.

from data given in reports by UNSCEAR $(1982,1993,2000)$. From these data one expects for a geographical latitude of $51^{\circ} \mathrm{N}$ a decay corrected ${ }^{137} \mathrm{Cs}$ fall-out for the 1980 s between $4.6 \mathrm{kBq} \mathrm{m}^{-2}$ and $5.2 \mathrm{kBq} \mathrm{m}^{-2}$, much closer to our estimates than to those by Mironov et al. (1999, 2002) and Straume et al. (2006). However, the preChernobyl fall-out of ${ }^{137} \mathrm{Cs}$ does not affect the conclusions regarding the fall-out due to the Chernobyl accident, the latter being much higher than the former.

In the case of ${ }^{129}$ I, the correction for pre-Chernobyl fall-out is crucial since it decides in which areas a retrospective dosimetry can be performed on the basis of ${ }^{129}$ I or not. The uncertainty $u\left(D_{\text {pre- }}\right.$ 

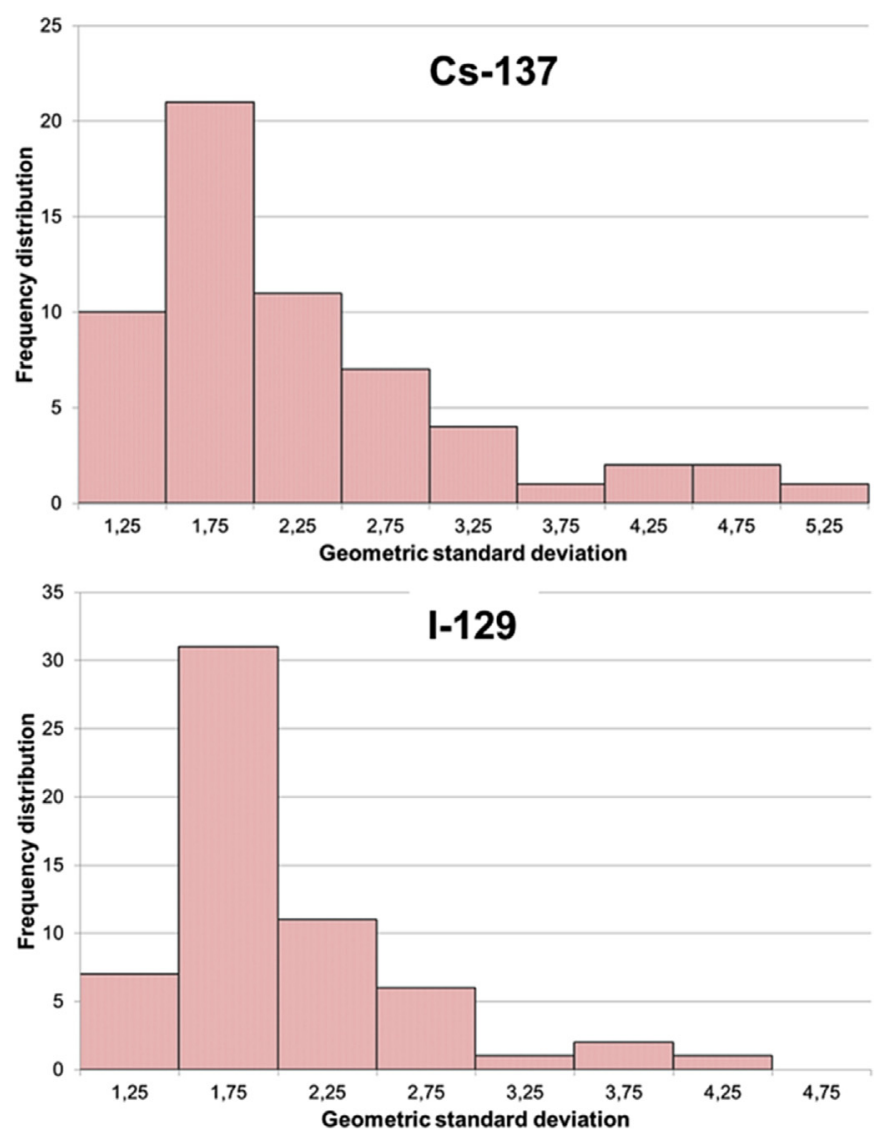

Fig. 6. Frequency distributions of the geometric standard deviations of the inventories derived from 5 soil samples for each settlement: ${ }^{137} \mathrm{Cs}$ (top) and ${ }^{129} \mathrm{I}$ (bottom).

Ch. $\left.\left({ }^{129} \mathrm{I}\right)\right)$ finally determines the threshold for a decision according to ISO 11929 (ISO, 2010) whether or not there is an additional contribution of Chernobyl fallout. Thus, the question of whether a retrospective dosimetry is feasible depends on how accurately the pre-Chernobyl fall-out can be determined. This holds also true for any other application of retrospective dosimetry such as in the case of the Fukushima accident.

However, the contamination with ${ }^{129}$ I resulting from the releases of the European reprocessing plants limits the applicability of the retrospective dosimetry on the basis of ${ }^{129} \mathrm{I}$. In this case ${ }^{137} \mathrm{Cs}$ is more favourable if the ${ }^{131} \mathrm{I} /{ }^{137} \mathrm{Cs}$ ratio in the fall-out can be reliably estimated.

The ${ }^{129}$ I and ${ }^{137} \mathrm{Cs}$ inventories from this work, both corrected for the pre-Chernobyl fall-out, are highly correlated (Fig. 5) with a correlation coefficient of $R^{2}=0.939$ and a correlation line according to Equation (3).

$$
\begin{aligned}
& D\left({ }^{129} \mathrm{I} \text { in } \mathrm{mBq} \mathrm{m}^{-2}\right)=0.18 \times 10^{-6} \times D\left({ }^{137} \mathrm{Cs} \text { in } \mathrm{kBq} \mathrm{m}^{-2}\right) \\
& +67 \mathrm{~Bq} \mathrm{~m} \mathrm{~m}^{-2}
\end{aligned}
$$

From Equation (3) one could conclude that the retrospective dosimetry of ${ }^{131}$ I exposures of the thyroid glands should be feasible by both nuclides ${ }^{129}$ I and ${ }^{137} \mathrm{Cs}$ in the area investigated. However, in spite of the good correlation between the ${ }^{129}$ I and ${ }^{137} \mathrm{Cs}$ inventories shown in Fig. 5, the variability of the ratios of the geometric means in each settlement was high. The $D\left({ }^{129} \mathrm{I}\right) / D\left({ }^{137} \mathrm{Cs}\right)$ ratios (in units of $10^{-6}$ ) varied in zone II from 0.064 to 0.43 and in zone III from 0.16 to 3.86. The latter high ratio was only observed for the village Sakusili.
Without this village the upper limit of the range of ratios was 0.83 . Therefore, in spite of the general applicability of both nuclides, ${ }^{129}$ I and ${ }^{137} \mathrm{Cs}$, for retrospective dosimetry ${ }^{129}$ I should be preferred because the variability of the Iodine/Caesium ratios in air and fallout does not enter into the retrospective dosimetry based on ${ }^{129} \mathrm{I}$.

The ratios $D\left({ }^{129} \mathrm{I}\right) / D\left({ }^{137} \mathrm{Cs}\right)$ of the total inventories of ${ }^{129} \mathrm{I}$ and of ${ }^{137} \mathrm{Cs}$ give some evidence for the origin of environmental ${ }^{129} \mathrm{I}$, since ${ }^{129} \mathrm{I}$ and ${ }^{137} \mathrm{Cs}$ from fission of ${ }^{235} \mathrm{U}$ and from unfractionated Chernobyl debris should represent the isobaric fission yields.

$$
\begin{aligned}
\frac{A_{\text {fission }}\left({ }^{129} \mathrm{I}\right)}{A_{\text {fission }}\left({ }^{137} \mathrm{Cs}\right)} & =\frac{Y(129) \cdot \lambda\left({ }^{129} \mathrm{I}\right)}{Y(137) \cdot \lambda\left({ }^{137} \mathrm{Cs}\right)}=\frac{0.0065 \cdot 1.4 \cdot 10^{-15} \mathrm{~s}^{-1}}{0.0626 \cdot 7.3 \cdot 10^{-10} \mathrm{~s}^{-1}} \\
& =2.0 \times 10^{-7}
\end{aligned}
$$

with

$Y(A)$ being the fission yield of the isobars $A=129$ and $A=137$ and

$\lambda$ the decay constants of ${ }^{129}$ I and ${ }^{137}$ Cs.

The ratio $A_{\text {fission }}\left({ }^{129} \mathrm{I}\right) / A_{\text {fission }}\left({ }^{137} \mathrm{Cs}\right)$ calculated by Equation (4) is surely within the uncertainty of the slope of the correlation line according to Equation (3) and shows that the so-called Western Cloud which contaminated the region investigated contained widely unfractionated Chernobyl debris. Mironov et al. (2002) reported a value of $2.75 \times 10^{-7}$ for the ${ }^{129} \mathrm{I} /{ }^{137} \mathrm{Cs}$ activity ratio at the time of the explosion of the Chernobyl Block 4. In that part of Northern Ukraine which was affected by the Western Cloud we find a significantly lower ratio of $1.8 \times 10^{-7}$. The mean ratio of ${ }^{129} \mathrm{I}$ and ${ }^{137} \mathrm{Cs}$ inventories is, however, relatively similar for Belarus, Poland and Ukraine.

\section{Modelling of thyroid doses}

The mathematical model underlying the retrospective dosimetry of ${ }^{131} \mathrm{I}$ exposures using ${ }^{129} \mathrm{I}$ is given by Equation (5).

$H_{\text {thyr }}=\left(D\left({ }^{129} \mathrm{I}\right)-D_{\text {pre-Ch. }}\left({ }^{129} \mathrm{I}\right)\right) \cdot \frac{A_{131}}{A_{129}} \cdot D C_{131} \cdot f(t)$

where

$H_{\text {thyr }}$ is the committed equivalent dose to the thyroid due to ${ }^{131} \mathrm{I}$ in $\mathrm{Sv}$,

$D\left({ }^{129} \mathrm{I}\right)$ the ${ }^{129} \mathrm{I}$ inventory at a location in $\mathrm{Bq}^{-2}$,

$D_{\text {pre-Ch. }}\left({ }^{129} \mathrm{I}\right)$ the ${ }^{129}$ I inventory from pre-Chernobyl fall-out in $\mathrm{Bq}$ $\mathrm{m}^{-2}$,

$\frac{A_{131}}{A_{129}}$ the activity ratio of ${ }^{131} \mathrm{I}$ and ${ }^{129} \mathrm{I}$ at the time of the accident, ${ }_{D C} C_{131}$ an aggregated dose coefficient for ${ }^{{ }^{131}}$ I exposure of the thyroid for a single fall-out event in $\mathrm{Sv} \mathrm{Bq}{ }^{-1} \mathrm{~m}^{2}$ derived from a radioecological model,

$f(t)$ a correction factor which accounts for the decay of ${ }^{131}$ I between the accident and arrival of the ${ }^{131} \mathrm{I}$ at the location of the exposure.

In the retrospective dosimetry based on ${ }^{137} \mathrm{Cs}$ inventories the thyroid equivalent doses are calculated by:

$H_{\text {thyr }}=\left(D\left({ }^{137} \mathrm{Cs}\right)-D_{\text {pre-Ch. }}\left({ }^{137} \mathrm{Cs}\right)\right) \cdot D C_{131}\left({ }^{137} C s\right)$

In Equation (6) the activity ratio of ${ }^{131} \mathrm{I}$ and ${ }^{137} \mathrm{Cs}$ at the time of the fall-out is not a parameter in the calculation because it is implicitly considered in the calculation of the dose coefficients $D C_{131}\left({ }^{137} \mathrm{Cs}\right)$ by Kruk et al. (2004). 
In the case of the Chernobyl accident, however, the different elements were chemically fractionated during the explosion and the subsequent emissions. They were further fractionated by a time dependent atmospheric transport of the plumes in the troposphere and by deposition with differing deposition velocities in the case of dry deposition and differing wash-out coefficients for iodine and caesium depending on their chemical and physical states; see UNSCEAR (2000) and references therein. In the parts of Northern Ukraine investigated in this work the correlation in Equation (3) allows also using ${ }^{137} \mathrm{Cs}$ for retrospective dosimetry, though there remains the caveat given above that the ${ }^{131} \mathrm{I} /{ }^{137} \mathrm{Cs}$ ratio has to be carefully investigated. In this work we rely more on the ${ }^{129} \mathrm{I}$ retrospective dosimetry because of the additional uncertainty introduced in the ${ }^{137} \mathrm{Cs}$ retrospective dosimetry by the variability of the Iodine/Caesium ratios in our samples and the larger variance of the ${ }^{137} \mathrm{Cs}$ inventories. In spite of these draw backs we shall also discuss the results for thyroid doses obtained by ${ }^{137} \mathrm{Cs}$.

We obtained data on measured time-integrated ${ }^{131}$ I activities of thyroid glands for 45 of our investigated settlements by courtesy of Peter Jacob (Table 2). From these data thyroid equivalent doses were calculated according to the work of Likhtarov et al. (1994) using Equation (7):

$$
D=\frac{E}{m} Q
$$

with

$D$ being the thyroid dose in Gy,

$E$ the decay energy per decay of ${ }^{131} \mathrm{I}$ in $\mathrm{J}\left(\mathrm{E}=3,6810^{-14} \mathrm{~J}\right)$,

Table 2

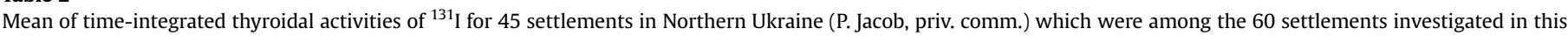
work.

\begin{tabular}{|c|c|c|c|c|c|c|c|c|}
\hline $\begin{array}{l}\text { Name of } \\
\text { settlement }\end{array}$ & $\begin{array}{l}\text { Contamination } \\
\text { zone }\end{array}$ & $\begin{array}{l}\text { Number } \\
\text { in Fig. } 1\end{array}$ & District & $\begin{array}{l}\text { Total number of } \\
\text { measured } \\
\text { individuals }\end{array}$ & $\begin{array}{l}\text { Northern } \\
\text { latitude in } \\
\text { decimal } \\
\text { degrees }\end{array}$ & $\begin{array}{l}\text { Eastern } \\
\text { longitude } \\
\text { in } \\
\text { decimal } \\
\text { degrees }\end{array}$ & $\begin{array}{l}\text { Mean of integrated } \\
\text { thyroidal activities of } \\
{ }^{131} \mathrm{I} \text { in } \mathrm{kBq} \text { day }\end{array}$ & $\begin{array}{l}\text { Arithmetic standard deviation of the } \\
\text { mean of integrated thyroidal activities of } \\
{ }^{131} \text { I in kBq day }\end{array}$ \\
\hline Motili & III & 2 & Naroditschi & 57 & 51.261 & 29.114 & 8191 & 9649 \\
\hline Perejizd & II & 8 & Owrutsch & 15 & 51.379 & 29.140 & 2130 & 1962 \\
\hline Stara Radtscha & III & 9 & Naroditschi & 89 & 51.357 & 29.307 & 2708 & 3088 \\
\hline Nowa Radtscha & III & 12 & Naroditschi & 57 & 51.251 & 29.134 & 2900 & 2990 \\
\hline Radtscha & III & 14 & Naroditschi & 9 & 51.379 & 29.298 & 3920 & 4217 \\
\hline Marjaniwka & III & 15 & Naroditschi & 9 & 51.331 & 29.270 & 6814 & 5205 \\
\hline Greslya & III & 16 & Naroditschi & 30 & 51.353 & 29.284 & 1964 & 1495 \\
\hline Klotschki & III & 17 & Naroditschi & 43 & 51.326 & 29.087 & 3863 & 2775 \\
\hline Lataschi & III & 18 & Naroditschi & 41 & 51.295 & 29.043 & 2847 & 1447 \\
\hline Starij Dorogin & III & 19 & Naroditschi & 81 & 51.257 & 29.154 & 4519 & 3046 \\
\hline Nowij Dorogin' & III & 20 & Naroditschi & 64 & 51.268 & 29.200 & 3904 & 2247 \\
\hline Zalissya & III & 21 & Naroditschi & 97 & 51.264 & 29.242 & 3716 & 4210 \\
\hline Tarasi & II & 23 & Poliske & 53 & 51.259 & 29.308 & 1912 & 2643 \\
\hline Snytyshche & III & 24 & Naroditschi & 33 & 51.274 & 29.037 & 3875 & 1790 \\
\hline Odrubi & III & 25 & Naroditschi & 12 & 51.272 & 29.127 & 3763 & 2681 \\
\hline Yagberen' & III & 26 & Naroditschi & 83 & 51.272 & 29.127 & 8338 & 10,166 \\
\hline Slawenschtschina & III & 27 & Naroditschi & 33 & 51.076 & 29.265 & 5092 & 2849 \\
\hline Hristiniwka & II & 28 & Naroditschi & 64 & 51.241 & 29.208 & 19,591 & 28,247 \\
\hline Polis'ke & II & 30 & Naroditschi & 33 & 51.086 & 29.205 & 6715 & 7514 \\
\hline $\begin{array}{l}\text { Polis'ke } \\
\text { (Korosten) }\end{array}$ & III & 31 & Poliske & 54 & 51.015 & 29.275 & 2386 & 2786 \\
\hline Nowe Scharno & II & 33 & Naroditschi & 48 & 51.230 & 29.187 & 16,438 & 13,581 \\
\hline Stare Scharno & II & 34 & Naroditschi & 69 & 51.216 & 29.152 & 7964 & 7910 \\
\hline Naroditschi & II & 35 & Naroditschi & 1546 & 51.211 & 29.087 & 4234 & 6629 \\
\hline Selets & II & 36 & Naroditschi & 218 & 51.187 & 29.031 & 7878 & 9032 \\
\hline Babinitschi & III & 37 & Naroditschi & 147 & 51.165 & 28.949 & 1160 & 1100 \\
\hline Sakusili & III & 38 & Naroditschi & 59 & 51.155 & 28.872 & 1348 & 1080 \\
\hline Jerew & III & 39 & Naroditschi & 74 & 51.173 & 28.980 & 1066 & 1089 \\
\hline $\begin{array}{l}\text { Sloboda- } \\
\text { V'yjazivka }\end{array}$ & III & 40 & Naroditschi & 118 & 51.261 & 29.080 & 1193 & 1172 \\
\hline Zwizdal' & II & 41 & Naroditschi & 33 & 51.173 & 29.244 & 6720 & 7013 \\
\hline Rozochiwske & II & 42 & Naroditschi & 12 & 51.129 & 29.012 & 3743 & 2150 \\
\hline Loznitsya & II & 43 & Naroditschi & 37 & 51.124 & 29.088 & 4353 & 4632 \\
\hline Mali Kleschtschi & II & 44 & Naroditschi & 46 & 51.124 & 29.162 & 8418 & 8910 \\
\hline Mali Minki & II & 45 & Naroditschi & 29 & 51.139 & 29.272 & 13,073 & 9195 \\
\hline $\begin{array}{l}\text { Rudnya } \\
\text { Ososchnya }\end{array}$ & II & 46 & Naroditschi & 37 & 51.150 & 29.352 & 10,083 & 18,598 \\
\hline Seweriwka & II & 47 & Naroditschi & 4 & 51.104 & 29.073 & 9928 & 35,197 \\
\hline Lyubarka & II & 48 & Naroditschi & 104 & 51.078 & 29.065 & 6756 & 6848 \\
\hline Rogi & II & 49 & Naroditschi & 4 & 51.071 & 29.099 & 4928 & 3456 \\
\hline $\begin{array}{l}\text { Weliki } \\
\text { Kleschtschi }\end{array}$ & II & 50 & Naroditschi & 111 & 51.066 & 29.177 & 5249 & 7020 \\
\hline Listiniwka & II & 51 & Naroditschi & 8 & 51.085 & 29.290 & 3651 & 1857 \\
\hline Weliki Min'ki & II & 52 & Naroditschi & 19 & 51.090 & 29.310 & 3419 & 3787 \\
\hline Rudnya Basars'ka & III & 53 & Naroditschi & 52 & 51.204 & 29.331 & 8068 & 13,835 \\
\hline Jurawlina & II & 54 & Naroditschi & 7 & 51.058 & 29.015 & 5762 & 3269 \\
\hline Bazar & II & 55 & Naroditschi & 514 & 51.045 & 29.294 & 1771 & 2576 \\
\hline Kaliniwka & II & 56 & Naroditschi & 144 & 51.022 & 29.090 & 3870 & 2872 \\
\hline Brodnik & III & 57 & Naroditschi & 20 & 51.160 & 28.917 & 1119 & 914 \\
\hline
\end{tabular}



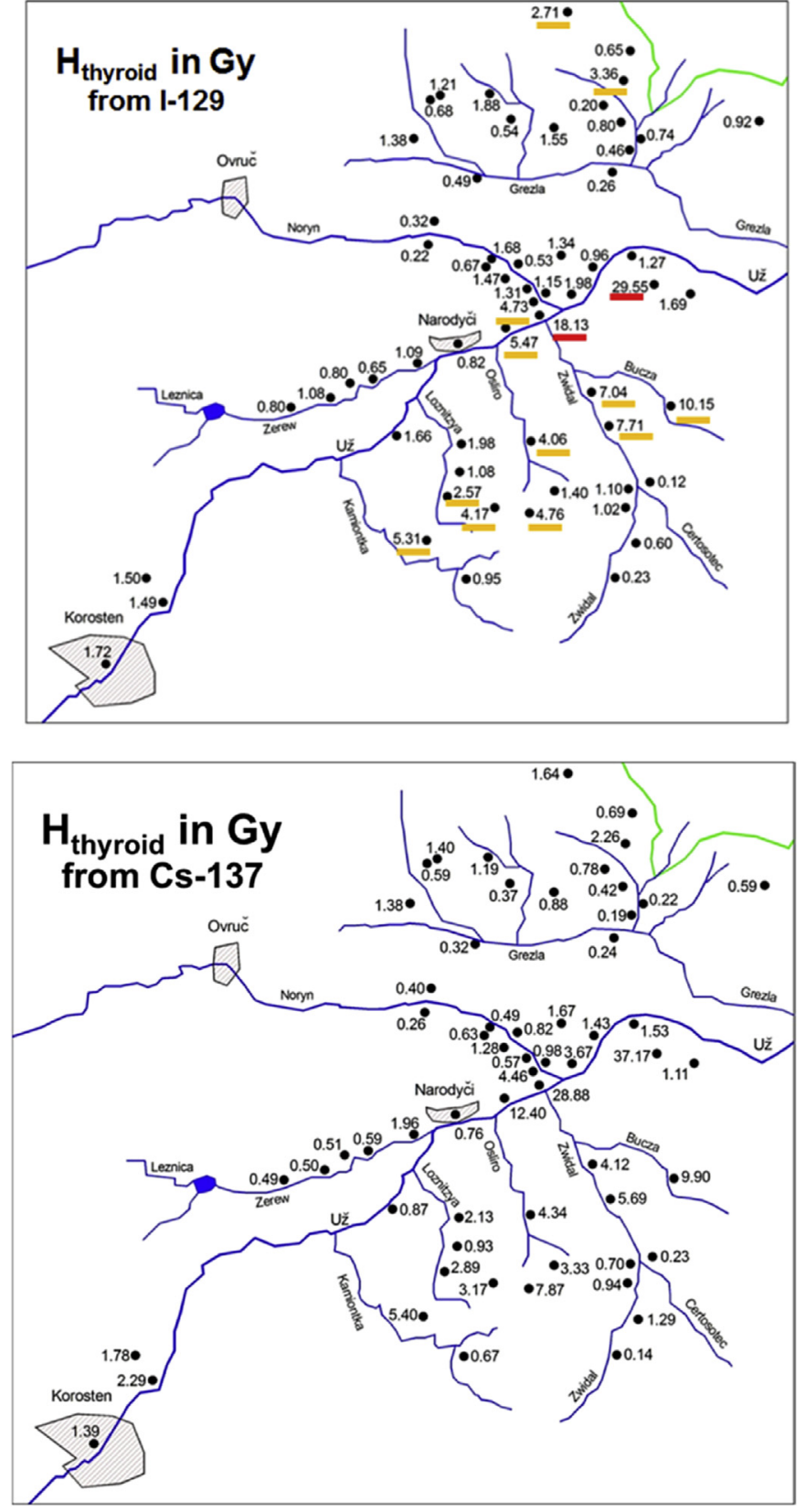

Fig. 7. Calculated thyroid equivalent dose $\mathrm{H}_{\text {thyroid }}$ for 5 -year-old in Gy through ${ }^{131} \mathrm{I}$, by means of the corrected ${ }^{129}$ I inventory (top) and by means of corrected ${ }^{137} \mathrm{Cs}$ inventory (bottom).

$Q$ the time-integrated ${ }^{131}$ I-activity in the thyroid gland in $\mathrm{Bq} \mathrm{s}$, and

$m$ the age dependent mass of the thyroid gland in $\mathrm{kg}$. Thyroid gland masses of $3.45 \mathrm{~g}$ for 5 -years-old children, $7.93 \mathrm{~g}$ for 10 years-old children and $20 \mathrm{~g}$ for adults were adopted (ICPR, 1989).

As discussed in detail by Michel et al. (2005) we prefer the estimate of the ${ }^{129} \mathrm{I} /{ }^{131} \mathrm{I}$ ratio based on the soil samples from Belarus. Belarus was the first country to receive the fresh fall-out and together with other Eastern European states is less affected by pre-Chernobyl fall-out. If the pre-Chernobyl fall-out is small then the smallest ${ }^{129} \mathrm{I} /{ }^{131}$ I isotopic ratio should have the highest credibility. The mean isotopic ratio calculated from the work of
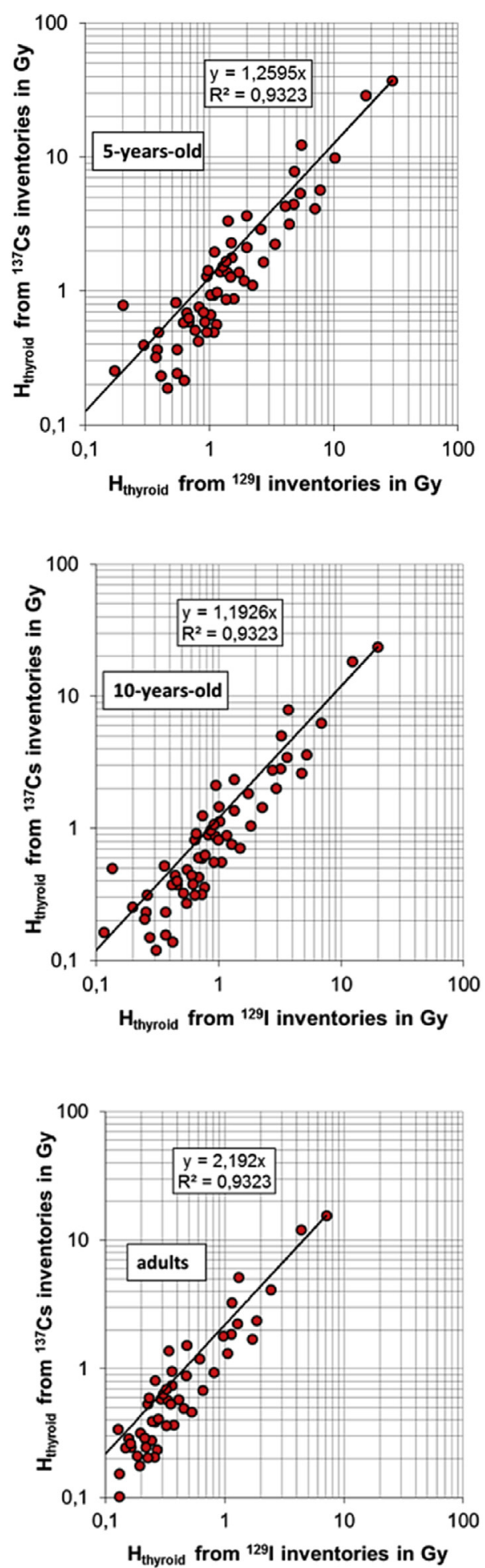

Fig. 8. Correlation between the thyroid equivalent doses $\mathrm{H}_{\text {thyroid }}$ for 5-years-old (top) and 10 -years-old children (middle) and adults (bottom) calculated by means of ${ }^{129} \mathrm{I}$ and ${ }^{137} \mathrm{Cs}$ inventories. The correlation line is forced through the point of origin.

Straume et al. (1996) and of Mironov et al. (2002) is ${ }^{129} \mathrm{I} /{ }^{131} \mathrm{I}=13.6 \pm 2.8$, which we assume here as the best estimate.

On the basis of the total ${ }^{129}$ I inventories corrected for the preChernobyl fall-out, the total ${ }^{131}$ I inventories were calculated using an initial isotopic ratio ${ }^{129} \mathrm{I} /{ }^{131} \mathrm{I}$ of the Chernobyl fall-out of $13.6 \pm 2.8$ equivalent to an activity ratio $A_{131} / A_{129}=(5.3 \pm 0.3) \cdot 10^{7}$. 

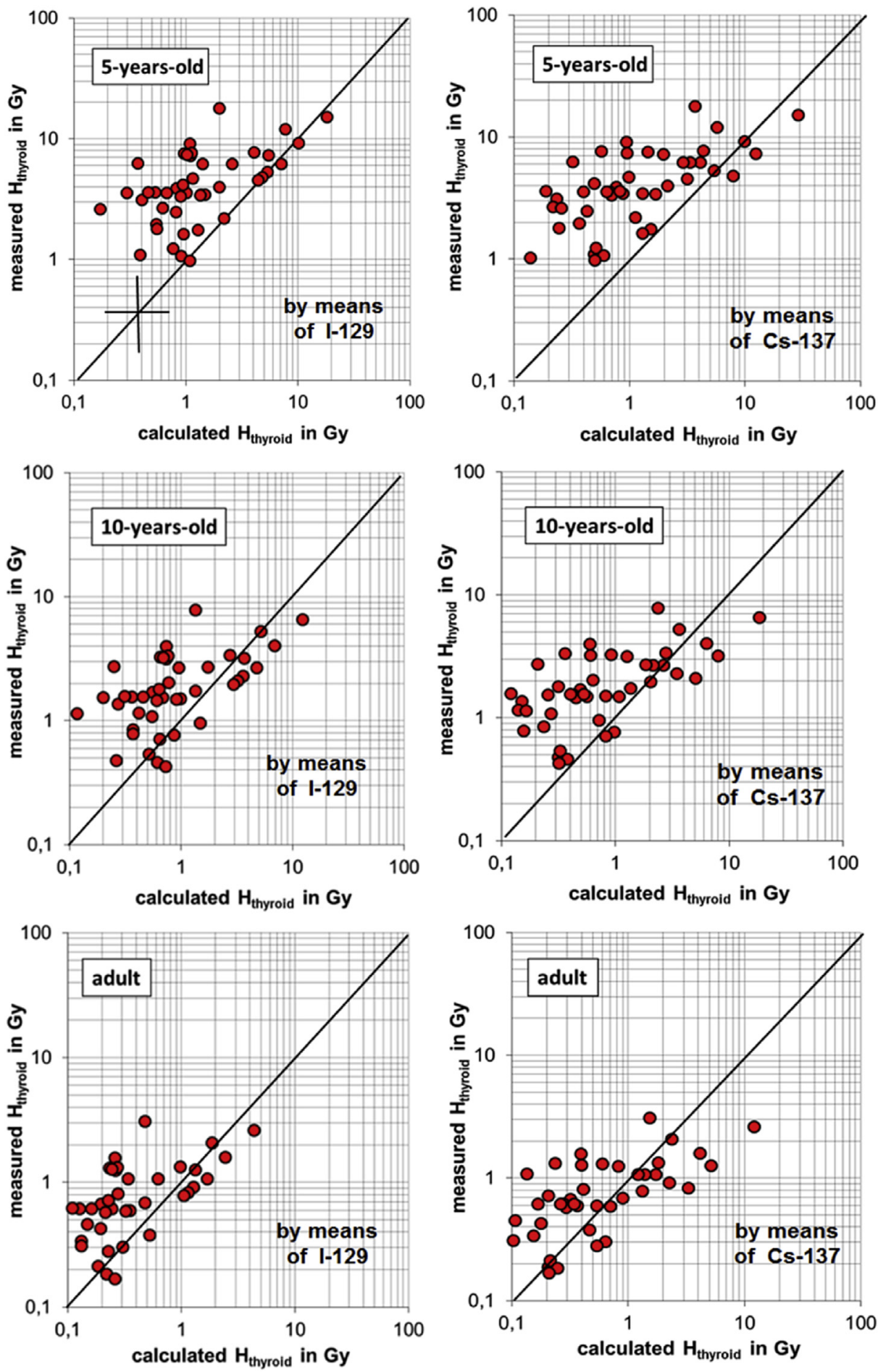

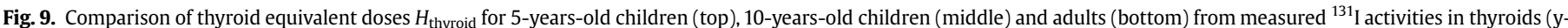

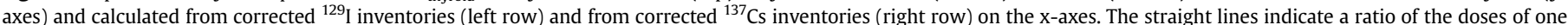
and the black cross a geometric standard deviation of two.

The geometric means of the total ${ }^{131}$ I inventories for the villages investigated in this work are given in Table 1 and Fig. 4.

The retrospective dosimetry of ${ }^{131}$ I exposures via ${ }^{129} \mathrm{I}$ ( or ${ }^{137} \mathrm{Cs}$ ) needs aggregated dose coefficients for ${ }^{131} \mathrm{I}$ in units of $\mathrm{Sv}$ per Bq $\mathrm{m}^{-2}$ to convert the total ${ }^{131}$ I inventory (derived from total ${ }^{129} \mathrm{I}$ or ${ }^{137} \mathrm{Cs}$ inventories) into estimates of ${ }^{131}$ I thyroid equivalent doses and consequently depends on the reliability of radioecological modelling.
Robl et al. (1997) used the ECOSYS model (Müller and Pröhl, 1993 ) to calculate the inhaled and ingested ${ }^{131}$ I activities depending on the particular weather conditions during fall-out. These authors emphasized that the main uncertainty in the model calculations depends on whether the fall-out occurred via wet or dry deposition. But, unfortunately, aggregated dose coefficients cannot be derived from the work of Robl et al. (1997).

In this work, as in our earlier work (Michel et al., 2005), we used 
the aggregated dose coefficients by Pietrzak Flis (2003) for calculating the thyroid equivalent doses due to ${ }^{131}$ I exposure. Up to now, Pietrzak-Flis et al. (2003) were the only authors reporting actual ${ }^{131}$ I dose estimates on the basis of a retrospective dosimetry using ${ }^{129}$ I. They used the CLRP model (Krajewski, 1996) in the form of a computer code CLRP by Krajewski (1999) to derive the required dose coefficients. From the data given in their publication, aggregated dose coefficients can be derived for 3 age groups. According to their model calculations, the dose coefficients for the committed thyroid equivalent doses are $(2.47 \pm 0.10) \times 10^{-7} \mathrm{~Sv} \mathrm{~Bq}^{-1} \mathrm{~m}^{2}$ for 5year-old children, $(1.67 \pm 0.10) \times 10^{-7} \mathrm{~Sv} \mathrm{~Bq}^{-1} \mathrm{~m}^{2}$ for 10 -year-old children, and $(5.92 \pm 0.30) \times 10^{-8} \mathrm{~Sv} \mathrm{~Bq}^{-1} \mathrm{~m}^{2}$ for adults. These dose coefficients were used in this work without taking into account their uncertainties.

For calculating thyroid equivalent doses based on the ${ }^{137} \mathrm{Cs}$ inventories we used the aggregated dose coefficients given by Kruk et al. (2004). The respective values are $(3.6 \pm 3.7) \mathrm{Sv} \mathrm{MBq}{ }^{-1} \mathrm{~m}^{2}$; $(2.3 \pm 2.4) \mathrm{Sv} \mathrm{MBq}^{-1} \mathrm{~m}^{2}$ and $(1.5 \pm 1.5) \mathrm{Sv} \mathrm{MBq}^{-1} \mathrm{~m}^{2}$ for 5 -years-old and 10-years-old children and for adults. Here, we applied these aggregated dose coefficients without taking into account their uncertainties.

We did not apply a time correction for the decay of ${ }^{131}$ I during the more than 10 days of releases or during the transport from the reactor to the settlements investigated. The explosion of block 4 of the Chernobyl NPP took place at 01:23 local time on April 26, 1986. The major releases of radionuclides lasted until May 6, 1986. The area investigated is located between $50 \mathrm{~km}$ and $100 \mathrm{~km}$ west to southwest of the NPP. It was affected mainly by the transition of the so-called western cloud which arrived before the afternoon of April 27, 1986 at Narodici. There is official evidence (photo of an official measurement protocol taken by one of the authors at a museum at Narodici) that the radioactive cloud had arrived already at 16:30 on April 27, 1986 at Narodici when a first measurement of an ambient dose rate of $30 \mathrm{mSv} / \mathrm{h}$ was reported. The ambient dose rates fell quickly, i.e. by more than 2 orders of magnitude until 18:00 on April 28,1986 and dropped to values around $10 \mu \mathrm{Sv} / \mathrm{h}$ to $20 \mu / \mathrm{h}$ from 18:00 on April 29, 1986.

For more detailed dose estimates more sophisticated aggregated dose coefficients are needed, combining fall-out calculations taking into account the actual weather conditions in April and May 1986 with realistic radioecological model calculations. Such calculations cannot be performed in this work because of lack of respective meteorological information. Calculations of the actual fall-out fields were performed by Talerko (2005), but a radioecological modelling of the transfer from fall-out to man considering the actual ecological conditions (meteorological situation, precipitation rates, occupancy times of the inhabitants of the settlements in-house and outside, consumption rates of milk and green vegetable) at the time of the accident are not at our disposal. Therefore, such a detailed modelling must remain beyond the scope of this publication.

\section{Thyroid doses derived from ${ }^{129}$ I and ${ }^{137} \mathrm{Cs}$ inventories}

In Table 1, we present the results for the thyroid exposures based on ${ }^{129} \mathrm{I}$ and ${ }^{137} \mathrm{Cs}$ inventories and on the aggregated dose coefficients deduced from the work of Pietrzak-Flis et al. (2003) and by Kruk et al. (2004), respectively.

The thyroid exposure is strongly age-dependent, mainly because of the increase of thyroid mass with age. In Fig. 7 the thyroid equivalent doses of 5-years-old children due to ${ }^{131}$ I derived from ${ }^{129} \mathrm{I}$ and ${ }^{137} \mathrm{Cs}$ inventories are overlaid on the map of the region. The highest thyroid doses for 5-years-old children are underlined to visualize the areas of highest exposures. The thyroid equivalent doses of 10 -years-old children and adults derived from ${ }^{129}$ I inventories are consistently lower than those of 5-years-old children by factors of 0.68 and 0.24 , respectively. Due to the method of retrospective dosimetry (based on ${ }^{129}$ I or ${ }^{137} \mathrm{Cs}$ ) these factors reveal simply the ratios of the respective aggregated dose coefficients.

It has to be emphasized that no countermeasures were undertaken in 1986 to prevent high thyroid exposures for the people living in the investigated part of Northern Ukraine and that the population was not even warned to stay at home or to avoid drinking milk or eating fresh vegetables and salad. The high thyroid doses given in Table 1 were the results of this policy. In 35 settlements of contamination zone II the geometric means of thyroid equivalent doses based on the ${ }^{129}$ I inventories were $\left(2.0 \times 3.0^{ \pm 1}\right) \mathrm{Gy}$ for 5-years-old children with a range from $0.2 \mathrm{~Gy}$ to $30 \mathrm{~Gy}$. For adults the mean thyroid equivalent doses were $\left(0.47 \times 3.1^{ \pm 1}\right) \mathrm{Gy}$ (ranging from 0.1 to $7.1 \mathrm{~Gy}$. In the 25 settlements of contamination zone III the mean thyroid equivalent doses were $\left(0.82 \times 1.8^{ \pm 1}\right) \mathrm{Gy}$ for 5-years-old children, ranging from 0.2 to $1.7 \mathrm{~Gy}$; for adults the mean value was $\left(0.21 \times 1.7^{ \pm 1}\right)$ Gy with a range from 0.1 Gy to $0.4 \mathrm{~Gy}$. The settlements with the highest calculated thyroid equivalent doses, namely Wladimirowka (29), Nowe Scharno (33) and Stare Scharno (34), were only evacuated on May 17, 1986, May 28, 1986 and May 26, 1986, respectively.

This variability of the ${ }^{131}$ I deposition is necessarily also revealed by the thyroid doses derived. There is just one clear distinction between zone II and zone III, i.e. that the thyroid doses in zone III are all below about 2 Gy while those in zone II go up to $30 \mathrm{~Gy}$. The limitation of the thyroid doses in zone III is an artefact due to fixing the upper limit of the ${ }^{137} \mathrm{Cs}$ fall-out at $555 \mathrm{kBq} \mathrm{m}^{-2}$. The thyroid doses calculated for the settlements of zone II span the entire range of results from $0.2 \mathrm{~Gy}$ up to the highest value.

All these dose estimates are in the range of thyroid doses (between $0.3 \mathrm{~Sv}$ und $40 \mathrm{~Sv}$ ) derived from measurements of children aged up to 7 from Gomel in Belarus (NEA, 1995). The estimates are also compatible with the thyroid exposures of children from Belarus reported by UNSCEAR (2000) and are well within the range of individual thyroid dose measurements in Northern Ukraine (Goulko et al., 1998). Typically, the latter individual doses show in each age group a high variability with ranges of an order of magnitude or more.

It is somewhat misleading if one speaks of thyroid equivalent doses because the values mentioned and given in Table 1 and Figs. 7-9 are geometric means (medians) and do not represent thyroid equivalent doses of individuals. The variability of the individual thyroid exposures is high and point estimates can just represent means or medians. This was shown already by Likhtarov et al. (1994) who compared individual thyroid equivalent doses measured in the village Rudka (Chernogov district) with model calculations based on the ECOSYS-87 code (Müller and Pröhl, 1993). They observed that measured thyroid doses spread around the modelled point estimates by about two orders of magnitude. This is consistent with geometric standard deviations of the individual thyroid doses of about 3.

As discussed by Likhtarov et al. (1994) these large geometric standard deviations are due to the distribution of the true individual doses within each of the age-gender groups (variability) and to the uncertainty of the measurements. They concluded that the distribution of individual doses each of the groups may be characterised by a geometric standard deviation of 2.0 , which means that there is a fair ( $5 \%$ ) chance for individuals to exceed the median point estimates of thyroid doses by a factor of four.

In our work, we assume that the uncertainties of the ${ }^{129}$ I and ${ }^{137}$ Cs inventories (Fig. 6) also apply to our dose estimates and give a rough estimate of what might be expected for the individual dose distributions. It is, however, likely that the geometric standard deviations are overestimating the real ones of the individual thyroid equivalent doses since they represent small scale variations of 
the radionuclide deposition while the thyroid exposures depend on medium scale contamination of the environment. The modes of the distributions of geometric standard deviations of nearly two may therefore be a better estimate of the variability of individual thyroid doses.

As for the ${ }^{129}$ I and ${ }^{137} \mathrm{Cs}$ inventories, the thyroid equivalent doses calculated from ${ }^{129}$ I and ${ }^{137} \mathrm{Cs}$ are necessarily highly correlated with each other.Fig. 8 shows this for the thyroid doses (geometric means) of Table 1. In Fig. 8 the uncertainties are omitted since they are the same as seen for the inventories in Fig. 5. The additional information provided by the correlation of the thyroid doses is that the dose coefficients used are not fully consistent which would require a correlation line with a slope of unity. The trend line of the data in Fig. 8 has an observed slope of $H_{\text {thyr }}\left({ }^{137} \mathrm{Cs}\right)=1.26 \times H_{\text {thyr }}\left({ }^{129} \mathrm{I}\right)$ in the case of 5-years-old children. For 10-years-old children and adults the slopes are somewhat different: 1.2 and 2.2, respectively. However, a correlation line with slope 1 surely is within the limits of the uncertainties of our individual estimates and shows the global agreement of the data. This does, however, not hold true if one compares the doses obtained for the individual settlements.

\section{Comparison of measured and retrospectively determined thyroid doses}

The results of the retrospective dosimetry can be compared with those based on measured time-integrated ${ }^{131}$ I activities in individual thyroid glands for 45 of the 60 settlements investigated. The arithmetic means of the time-integrated ${ }^{131}$ I activities in individual thyroid glands (Table 2) typically have arithmetic standard deviations which often exceed the; not uncommon for logarithmic normal distributions with substantial geometric standard deviations. Unfortunately, we do not have the geometric standard deviations, which should be around three according to Likhtarov et al. (1994).

In Fig. 9 we compare the thyroid equivalent doses calculated by equation (7) from the time-integrated ${ }^{131}$ I activities in the thyroid glands with those derived by retrospective dosimetry on the basis of ${ }^{129}$ I and ${ }^{137}$ Cs. We will, however, base our discussion of Fig. 8 mainly on the results obtained from ${ }^{129} \mathrm{I}$.

According to Fig. 8, the retrospective data represent more or less lower limits to the doses derived from time-integrated ${ }^{131}$ I activities. In Fig. 9, for retrospective thyroid doses above 2 Gy both estimates agree within the underlying uncertainties. To give a rough impression of the uncertainties a cross representing geometric standard deviations of two is given in the figure for the 5-years-old children. Below retrospective thyroid doses of $2 \mathrm{~Gy}$, however, there appears to be a substantial underestimation of thyroid exposures by the retrospective dosimetry. We interpret this as follows: The dose coefficients by Pietrzak Flis (2003) are for an exposure situation dominated by ingestion of ${ }^{131} \mathrm{I}$; inhalation is supposed to play a minor role. The deposition data represented by the ${ }^{129} \mathrm{I}$ (and ${ }^{137} \mathrm{Cs}$ ) inventories clearly provide a good basis to estimate the ingestion pathway, but they do not allow estimating the exposure via the inhalation pathway. If a highly contaminated cloud passes without wet deposition there will be relatively moderate deposition while the inhalation doses can be high. This appears to be a possible explanation for the retrospective thyroid doses below 2 Gy being lower than those derived from the measurements of ${ }^{131} \mathrm{I}$ in the thyroids (Fig 9.).

The observed discrepancy is most pronounced in the case of the 5 -years-old children and becomes less significant for 10 -years-old ones and adults. But, this is simply the effect of smaller dose coefficients for the older ones.

Generally, one can state that the retrospective data based on ${ }^{129}$ I look a little better than those based on ${ }^{137} \mathrm{Cs}$, the latter tend to underestimate the thyroid exposures for the children, while for the adults the data look somewhat better. But, given the discussion above regarding the unanswered question of Iodine/Caesium ratios the retrospective dosimetry by ${ }^{129}$ I should be preferred.

As demonstrated in this work, for the situation in Northern Ukraine in 1986, the retrospective dosimetry based on ${ }^{129}$ I can provide lower limits of the actual exposures. In situations in which the ingestion pathway is dominating it can be considered as very useful tool. It does not allow giving a valid estimate or upper limits of thyroid exposures in cases where the inhalation pathway is dominating and if countermeasures such as a food ban are applied. In the latter case the ${ }^{129}$ I inventories can, however, provide a useful tool to benchmark and to improve the atmospheric transport and deposition calculations on which the inhalation doses have then to be based. This tool remains useful long after the short-lived ${ }^{131}$ I has decayed.

\section{Conclusions}

Retrospective analyses of the thyroid exposures due to ${ }^{131}$ I after the Chernobyl accident were performed for 60 settlements in Northern Ukraine based on analyses of ${ }^{129}$ I and ${ }^{137} \mathrm{Cs}$ in soils and using aggregated dose coefficients for 5-year old and 10-year-old children as well as for adults from radioecological modelling by Pietrzak Flis (2003) and Kruk et al. (2004), respectively.

The uncertainty of the ${ }^{129} \mathrm{I}$ and ${ }^{137} \mathrm{Cs}$ inventories in the soils were estimated from the variability observed for 5 samples taken for each settlement. The ${ }^{129}$ I and ${ }^{137} \mathrm{Cs}$ inventories were well correlated, the variability of the individual ${ }^{129} \mathrm{I} /{ }^{137} \mathrm{Cs}$ ratios and consequently the uncertainties of the dose estimate being, however, high.

The results demonstrate the extremely high thyroid exposures in many settlements of Northern Ukraine where no countermeasures were applied and where evacuations and resettlements took place only after the ${ }^{131}$ I exposure had happened. The highest thyroid equivalent doses (calculated from ${ }^{129}$ I inventories) were calculated for Wladimirowka with 30 Gy for 5-years-old children and $7 \mathrm{~Gy}$ for adults. In 35 settlements evacuated from contamination zone II, the geometric mean of the thyroid equivalent doses was $2.0 \mathrm{~Gy}$ for 5-years-old children with a geometric standard deviation (GSD) of 3.0. For adults the geometric mean was $0.47 \mathrm{~Gy}$ also with a GSD of 3.0. In more than 25 settlements of the not evacuated contamination zone III the geometric means were 0.82 Gy for 5-years old children with a GSD of 1.8 and $0.21 \mathrm{~Gy}$ for adults (GSD 1.8).

The thyroid doses calculated from the ${ }^{137} \mathrm{Cs}$ inventories agree well with those derived by ${ }^{129} \mathrm{I}$. This fact is not surprising given the good correlation between the inventories of the two nuclides in the soils in this part of Northern Ukraine. However, the variability of the ${ }^{137}$ Cs inventories was higher than that of the ${ }^{129}$ I inventories thus adding an additional uncertainty to the dose estimates.

Since such a good correlation cannot be presumed for other regions affected by the Chernobyl accident and since the Iodine/ Caesium ratio in fall-out can be influenced by the transport and deposition conditions and given the observed larger variability of the ${ }^{137} \mathrm{Cs}$ inventories, we conclude that retrospective dosimetry of thyroid exposure due to ${ }^{131}$ I on the basis of ${ }^{129}$ I after the Chernobyl accident is preferable.

For low thyroid exposures due to ${ }^{131}$ I, the per-accidental contamination of the territory with ${ }^{129} \mathrm{I}$ and ${ }^{137} \mathrm{Cs}$ has to be taken into account. For ${ }^{137} \mathrm{Cs}$ this turned out to be of minor importance, while for ${ }^{129}$ I in Europe the impact of the atmospheric nuclear weapons test and - to a much larger degree - of the European reprocessing plants limits the applicability of the ${ }^{129}$ I retrospective 
dosimetry to relatively high thyroid exposures.

For 45 settlements, the results of the retrospective dosimetry could be compared with thyroid equivalent doses calculated using time-integrated ${ }^{131}$ I activities of thyroids which were measured in 1986. Thus, a critical comparison of the results was possible which demonstrated the general feasibility of the retrospective dosimetry, but also the associated uncertainties and limitations.

Retrospective dosimetry can yield valuable information on the radiation exposure due to ${ }^{131} \mathrm{I}$ in areas where no direct measurements of thyroids exist. The knowledge of the pre-accident contamination is essential. It can be directly applied to situations where the ingestion pathway dominates the thyroid exposure. If the inhalation dominates and if countermeasures block the ingestion pathway, ${ }^{129}$ I inventories can serve to benchmark and improve the atmospheric transport and deposition calculations.

As a general lesson it can be concluded, that direct measurements of the thyroids after an accident have to be preferred and should be foreseen in any nuclear emergency planning. However, for areas where such measurements are not available, retrospective dosimetry via ${ }^{129}$ I will be a valuable tool to assess the consequences of the accident. In such circumstances, case specific aggregated dose coefficients should be established by collecting information on all the factors relevant for the radioecological modelling. Such an opportunity was not available in this work.

\section{Acknowledgements}

The authors are grateful to Peter Jacob (Institute of Radiation Protection ISS, HMGU, Munich) for providing the data of measured ${ }^{131}$ I in thyroid glands in Northern Ukraine.

\section{Appendix A. Supplementary data}

Supplementary data related to this article can be found at http:// dx.doi.org/10.1016/j.jenvrad.2015.07.023.

\section{References}

Botsch, W., Romantschuk, L.D., Handl, J., Beltz, D., Michel, R., May 14 - 19, 2000. Experimental investigations on the radiation exposure of inhabitants of contaminated areas in Northern Ukraine. In: Proceedings IRPA10, Hiroshima. CD P-11-254.

Daraoui, A., 2010. Migration von Iod-129 und retrospektive Dosimetrie. PhD thesis. Leibniz Universität, Hannover. http://edok01.tib.uni-hannover.de/edoks/ e01dh10/62787097X.pdf.

Daraoui, A., Michel, R., Gorny, M., Jakob, D., Sachse, R., Synal, H.-A., Alfimov, V., 2012. Iodine-129, Iodine-127 and Cesium-137 in the environment: soils from Germany and Chile. J. Environ. Radioact. 112, 8-22. http://dx.doi.org/10.1016/j. jenvrad.2012.02.011.

Endo, S., Tomita, J., Tanaka, K., Yamamoto, M., Fukutani, S., Imanaka, T., Sakaguchi, A., Amano, H., Kawamura, H., Kawamura, H., Apsalikov, K.N., Gusev, B.I., Whitehead, N.E., Shinkarev, S., Hoshi, M., 2008. Iodine-129 measurements in soil samples from Dolon village near the Semipalatinsk nuclear test site. Rad. Environ. Biophys. 47 (3), 359-365.

Ernst, T., Szidat, S., Handl, J., Jakob, D., Michel, R., Schnabel, C., Synal, H.-A., Santos Arevalo, F.J., Benne, I., Boess, J., Gehrt, E., Capelle, A., Schneider, J., Schäfer, W. Böttcher, J., 2003. Migration of iodine-129 and iodine-127 in soils. Kerntechnik 68, 155-167.

Filss, M., Botsch, W., Handl, J., Michel, R., 1998. A fast method for the determination of strontium-89 and strontium-90 in environmental samples and its application to the analysis of strontium-90 in Ukrainian soils. Radiochim. Acta 83, 81-92.

Goulko, G.M., Chepurny, N.I., Jacob, P., Kairo, I.A., Likhtarev, I.A., Pröhl, G., Sobolev, B.G., 1998. Thyroid dose and thyroid cancer incidence after the Chernobyl accident: assessments for the Zhytomyr region (Ukraine). Radiat. Environ. Biophys. 36, 216-273.

Handl, J., Beltz, D., Botsch, W., Harb, S., Jakob, D., Beltz, D., Michel, R., Romantschuk, L.D., 2003. Fall-out and transfer into the human food chain of cesium-137 and the radiation exposure of inhabitants of contaminated areas in Northern Ukraine. Health Phys. 84, 502-517.

Hippler, S., 2006. Strahlenexpsoition durch anthropogene Actinoide in der nördlichen Ukraine. PhD thesis. Leibniz Universität, Hannover. http://edok01. tib.uni-hannover.de/edoks/e01dh06/519958691.pdf.

ICPR, 1989. International Commission on Radiological Protection. Report of the Task
Group of committee 2, Dosimertic Models, ICPR Publication 50. Pergamon Press, Oxford.

ISO Guide to the Expression of Uncertainty in Measurement, 1995. ISO International Organization for Standardization, Geneva, 1993, corrected reprint JCGM 100 2008.

ISO, 2010. ISO 11929:2010, Determination of Detection Limit and Decision Threshold for Ionizing Radiation Measurements. Fundamentals and Applications. ISO, Geneva.

Jacob, P., Bogdanova, T.I., Buglova, E., Chepurniy, M., Demidchik, Y., Gavrilin, Y. Kenigsberg, J., Meckbach, R., Schotola, C., Shinkarev, S., Tronko, M.D. Ulanovsky, A., Vavilov, S., Walsh, L., 2006. Thyroid cancer risk in areas of Ukraine and Belarus affected by the Chernobyl accident. Radiat. Res. 165 (1), $1-8$.

Krajewski, P., 1996. CLRP Version 4.2 MANUAL. BIOMOVS II Technical Report No 7. Uncertainty and validation effect of user interpretation on uncertainty estimates. BIOMOVS Steering Committee, Stockholm.

Krajewski, P., 1999. Evaluation and Verification of Dose Assessment Model for Radioiodine and Radiocaesium Environmental Releases. Dissertation, Warsaw (in Polish).

Kruk, J.E., Pröhl, G., Kenigsberg, J.I., 2004 Jul. A radioecological model for the thyroid dose reconstruction of the population of Belarus after the Chernobyl accident,. Radiat. Environ. Biophys. 43 (2), 101-110. Epub 2004 Jun 19.

Law of Ukraine No. 796-XII: on the Status and Social Protection of Citizens, Who Have Suffered as a Consequence of the Chernobyl Catastrophe, 28.2.1991, p. 220. VVR 191, No. 16.

Likhtarov, I.A., Gulko, G.M., Sobolev, B.G., Kairo, I.A., Chepurnoy, N.I., Pröhl, G., Henrich, K., 1994. Thyroid dose assessment for the Chernigov region (Ukraine): estimation based on ${ }^{131}$ I thyroid measurements and extrapolation of the results to districts without monitoring. Radiat. Environ. Biophys. 33, 149-166.

Mewis, A., 2004. Strontium-90 in der Umwelt: Migrationsverhalten im Boden, Transfer in die Nahrungskette und Strahlenexposition in der nördlichen Ukraine. PhD thesis. Leibniz Universität, Hannover. http://edok01.tib.unihannover.de/edoks/e01dh04/389687499.pdf.

Michel, R., 2000. Quality assurance of nuclear analytical techniques based on Bayesian characteristic limits. J. Radioanal. Chem. 245, 137-144.

Michel, R., Handl, J., Ernst, T., Botsch, W., Szidat, S., Schmidt, A., Jakob, D., Beltz, D. Romantschuk, L.D., Synal, H.A., Schnabel, C., López-Gutiérrez, J.M., 2005. Iodine129 in soils from Northern Ukraine and the retrospective dosimetry of the iodine-131 exposure after the Chernobyl accident. Sci. Total Environ. 340, 35-55.

Michel, R., Daraoui, A., Gorny, M., Jakob, D., Sachse, R., Tosch, L., Nies, H., Goroncy, I., Herrmann, J., Synal, H.-A., Stocker, M., Alfimov, V., 2012. Iodine-129 and Iodine127 in European Seawaters and in Precipitation from Northern Germany. Sci. Total Environ. 419, 151-169.

Ministry of Ukraine of Emergencies and Affairs of Population Protection from the Consequences of Chornobyl Catastrophe, Intelligence Systems GEO, Ud, 2008. Atlas Ukraine radioactive contamination, Kyiv.

Mironov, V., Kudriaschov, V., Krivomas, M., Drugatschenok, M., Schmura, G., Yiou, F. Raisbek, G., Gall, P., 1999. Application of ${ }^{129}$ I as Indicator for the Reconstruction of the ${ }^{131}$ I Content in Human Thyroid Glands as a Consequence of the Chernobyl Accident. ed. IRB-2. Belarussian Academy of Scinece, Institute for Radiobiology, Minsk (in Russian).

Mironov, V., Kudrjashov, V., Yiou, F., Raisbeck, G.M., 2002. Use of ${ }^{129} \mathrm{I}$ and ${ }^{137} \mathrm{Cs}$ in soils fort he estimation of ${ }^{131}$ I deposition in Belarus as a result of the Chernobyl accident. J. Environ. Radioact. 59, 293-307.

Miyake, Y., Matsuzaki, H., Fujiwara, T., Saito, T., Yamagata, T., Honda, M., Muramatsu, Y., 2012. Isotopic ratio of radioactive iodine $\left({ }^{129} \mathrm{I} /{ }^{131} \mathrm{I}\right)$ released from Fukushima Daiichi NPP accident. Geochem. J. 46, 327-333.

Müller, H., Pröhl, G., 1993. ECOSYS-87: a dynamic model for assessing radiological consequences of nuclear accidents. Health Phys. 63, 232-252.

NEA, 1995. Chernobyl - Ten Years. On Radiological and Health Impact; an Assessment by the NEA Committee on Radiation Protection and Public Health. Nuclear Energy Agency, Paris.

Oktay, S.D., Santschi, P.H., Moran, J.E., Sharma, P., 2000. The Iodine-129 bomb pulse recorded in Mississippi River Delta Sediments: results from isotopes of I, Pu, Cs, $\mathrm{Pb}$ and C. Geochim. Cosmochim. Acta 64, 989-996.

Pietrzak-Flis, Z., Krajewski, P., Radwan, I., Muramatsu, Y., 2003. Retrospective evaluation of ${ }^{131}$ I deposition density and thyroid dose in Poland after the Chernobyl accident. Health Phys. 84, 698-708.

Rao, U., Fehn, U., 1999. Sources and reservoirs of anthropogenic Iodine-129 in western New York. Geochim. Cosmochim. Acta 63, 1927-1938.

Reithmeier, H., Lazarev, V., Rühm, W., Blinov, A., Huber, T., Kubo, F., Nolte, E., 2002 ${ }^{131}$ I Dose Reconstruction in the Former Soviet-Union (FSU) by Measurement of ${ }^{129}$ I. Annual Report 2001. Beschleunigerlaboratorium der Universität und Technischen Universität München, p. 25.

Roberts, M.L., Caffee, M.W., 2000. ${ }^{129}$ I interlaboratory comparison: phase II results Nucl. Instr. Meth Phys. Res. B172, 388-394.

Roberts, M.L., Caffee, M.W., Proctor, I.D., 1997. ${ }^{129}$ I interlaboratory comparison. Nucl. Instr. Meth Phys. Res. B123, 367-370.

Robl, R., Voigt, G., Paretzke, H.G., 1997. Rekonstruktion der Schilddrüsendosis für Kinder mit Schilddrüsenkrebs in Weissrussland. GSF-Bericht 24/97 (in German).

Schink, D.R., Santschi, P.H., Corapcioglu, O., Fehn, U., 1995. Prospects for iodine-129 dating of marine organic matter using AMS. Nucl. Instrum. Methods Phys. Res. B99, 524-527. 
Schmidt, A., Schnabel, C., Handl, J., Jakob, D., Michel, R., Synal, H.-A., Lopez, J.M. Suter, M., 1998. On the analysis of iodine-129 and iodine-127 in environmental materials by accelerator mass spectrometry and ion chromatography. Sci. Total Environ. 223, 131-156.

Schwinger, A.M., 2014. Deutschlandweite Untersuchung der ${ }^{129}$ I- und ${ }^{127}$ I-Inventare und ihres Isotopenverhältnisses in verschiedenen Umweltkompartimenten. PhD thesis. Leibniz Universität, Hannover. http://www.irs.uni-hannover.de/3. html.

Slavov, V.P. Didukh, M.I., Borshenko, V.V. Malarchiuk, P.M., Michel, R., Handl, J., 1999. Vertical Migration of ${ }^{137} \mathrm{Cs}$ and ${ }^{129}$ I Chornobyl's Origin in Turf-podsol Soils of Ukrainian Polissya. News of Agrarian Sciences - Kiiv: Agrarna nauka, 1997, special issue August 1997, pp. 27-30 (in Ukrainian).

Songsheng, J., Chang, Z., Zhao, M., Zhao, Y., Zhao, X.L., Kieser, W.E., 2005. New measurement of ${ }^{129}$ I in IAEA-375 reference material. J. Radioanal. Nucl. Chem. 264 (3), 549-553.

Stocker, M., Döbeli, M., Grajcar, M., Suter, M., Synal, H.-A., Wacker, L., 2005 A universal and competitive compact AMS facility. Nucl. Instrum. Meth Phys. Res. B 240, 483-489.

Straume, T., Anspaugh, L.R., Marchetti, A.A., Voigt, G., Minenko, V., Gu, F., Men, P. Trofimik, S. Tretyakevich, S. Drozdovitch, V., Shagalova, E. Zhukova, O. Germenchuk, M., Berlovich, S., 2006. Measurement of ${ }^{129} \mathrm{I}$ and ${ }^{137} \mathrm{Cs}$ in soils from Belarus and reconstruction of ${ }^{131}$ I deposition from the Chernobyl accident. Health Phys. 91 (1), 7-19.

Straume, T., Marchetti, A.A., Anspaugh, L.R., Khrough, V.T., Gavrilin, Y.I Shinkarev, S.M., Drozdovitch, V.V., Ulanovski, A.V., Korneev, S.V., Brekeshev, M.K., Leonov, E.S., Voigt, G., Pachenko, S.V., Minenko, V.F., 1996. The feasibility of using ${ }^{129}$ I to reconstruct ${ }^{131}$ I deposition from the Chernobyl reactor accident. Health Phys. 71, 733-740.

Szidat, S., Schmidt, A., Handl, J., Jakob, D., Michel, R., Synal, H.-A., Schnabel, C., Suter, M., Lopez-Gutierrez, J.M., 2000a. RNAA and AMS of iodine-129 in environmental materials - comparison of analytical methods and quality assurance. Kerntechnik 65, 160-167.

Szidat, S., Schmidt, A., Handl, J., Jakob, D., Botsch, W., Michel, R., Synal, H.-A., Schnabel, C., Suter, M., López-Gutiérrez, J.M., Städe, W., 2000b. Iodine-129: sample preparation, quality control and analyses of pre-nuclear materials and of natural waters from Lower Saxony, Germany. Nucl. Instr. Meth Phys. Res. B172, 699-710.

Szidat, S., Schmidt, A., Handl, J., Jakob, D., Michel, R., Synal, H.-A., Suter, M., 2000c. Analysis of iodine-129 in environmental materials: quality assurance and applications. J. Radioanal. Chem. 244, 45-50.

Talerko, N., 2005. Reconstruction of ${ }^{131}$ I radioactive contamination in Ukraine caused by the Chernobyl accident using atmospheric transport modelling. J. Environ. Radioact. 84, 343-362.

UNSCEAR, 1982. Report of the United Nations Scientific Committee on the Effects of Atomic Radiation Ionizing Radiation to the General Assembly. With Scientific Annexes. United Nations.

UNSCEAR, 1993. Report of the United Nations Scientific Committee on the Effects of Atomic Radiation Ionizing Radiation to the General Assembly, with Scientific Annexes. United Nations.

UNSCEAR, 2000. Report of the United Nations Scientific Committee on the Effects of Atomic Radiation to the General Assembly. ANNEX J Exposures and effects of the Chernobyl accident. United Nations. 